\title{
Production of L-lactic acid by the yeast Candida sonorensis expressing heterologous bacterial and fungal lactate dehydrogenases
}

\author{
Marja IImén ${ }^{1 *}$, Kari Koivuranta ${ }^{1}$, Laura Ruohonen ${ }^{1}$, Vineet Rajgarhia ${ }^{2,3}$, Pirkko Suominen ${ }^{2}$ and Merja Penttilä
}

\begin{abstract}
Background: Polylactic acid is a renewable raw material that is increasingly used in the manufacture of bioplastics, which offers a more sustainable alternative to materials derived from fossil resources. Both lactic acid bacteria and genetically engineered yeast have been implemented in commercial scale in biotechnological production of lactic acid. In the present work, genes encoding L-lactate dehydrogenase $(L D H)$ of Lactobacillus helveticus, Bacillus megaterium and Rhizopus oryzae were expressed in a new host organism, the non-conventional yeast Candida sonorensis, with or without the competing ethanol fermentation pathway.

Results: Each LDH strain produced substantial amounts of lactate, but the properties of the heterologous LDH affected the distribution of carbon between lactate and by-products significantly, which was reflected in extra-and intracellular metabolite concentrations. Under neutralizing conditions C. sonorensis expressing L. helveticus LDH accumulated lactate up to $92 \mathrm{~g} / \mathrm{l}$ at a yield of $0.94 \mathrm{~g} / \mathrm{g}$ glucose, free of ethanol, in minimal medium containing $5 \mathrm{~g} / \mathrm{l}$ dry cell weight. In rich medium with a final $\mathrm{pH}$ of $3.8,49 \mathrm{~g} / \mathrm{l}$ lactate was produced. The fermentation pathway was modified in some of the strains studied by deleting either one or both of the pyruvate decarboxylase encoding genes, $P D C 1$ and PDC2. The deletion of both PDC genes together abolished ethanol production and did not result in significantly reduced growth characteristic to Saccharomyces cerevisiae deleted of PDC1 and PDC5.
\end{abstract}

Conclusions: We developed an organism without previous record of genetic engineering to produce L-lactic acid to a high concentration, introducing a novel host for the production of an industrially important metabolite, and opening the way for exploiting C. sonorensis in additional biotechnological applications. Comparison of metabolite production, growth, and enzyme activities in a representative set of transformed strains expressing different $L D H$ genes in the presence and absence of a functional ethanol pathway, at neutral and low $\mathrm{pH}$, generated a comprehensive picture of lactic acid production in this yeast. The findings are applicable in generation other lactic acid producing yeast, thus providing a significant contribution to the field of biotechnical production of lactic acid.

\section{Background}

A variety of new products based on polymerized lactic acid are constantly being developed, increasing the demand for lactic acid. L-Lactic acid is typically produced in large quantities by carbohydrate fermentation by lactic acid bacteria. The fermentation is efficient at near neutral $\mathrm{pH}$, controlled with neutralizing chemicals and generating lactate salts [1]. The undissociated (free) lactic acid rather than the salt of the acid is the required product for the polymerization reaction and additional

\footnotetext{
*Correspondence: marja.ilmen@vtt.fi

${ }^{1} \mathrm{VTT}$ Technical Research Centre of Finland, Espoo, Finland

Full list of author information is available at the end of the article
}

processing is necessary to recover free lactic acid. Yeast are considered as attractive alternative hosts for lactic acid production at low $\mathrm{pH}$ because they are more acid tolerant than lactic acid bacteria. Low $\mathrm{pH}$ production would decrease the need for neutralizing chemicals. Several groups have demonstrated efficient production of L-lactic acid by S. cerevisiae expressing a heterologous gene encoding lactate dehydrogenase $(L D H)[2-4]$. The $L D H$ gene has also been introduced into some nonconventional yeast species that have advantageous characteristics such as good acid tolerance or ability to metabolize carbohydrates that $S$. cerevisiae does not naturally consume. For example, Kluyveromyces lactis [5,6],

\section{() Biomed Central}

(c) 2013 IImén et al.; licensee BioMed Central Ltd. This is an Open Access article distributed under the terms of the Creative Commons Attribution License (http://creativecommons.org/licenses/by/2.0), which permits unrestricted use, distribution, and reproduction in any medium, provided the original work is properly cited. 
Pichia stipitis [7], Candida boidinii [8] and Candida utilis [9] have been shown to produce high concentrations of lactic acid. In addition, e.g. Zygosaccharomyces bailii [10], and Kluyveromyces marxianus [11] expressing $L D H$ have been shown to produce lactic acid.

One of the main issues related to lactic acid production using yeast, especially $S$. cerevisiae, is the ability of the yeast to produce ethanol in the presence of excess glucose. Even though the expression of the lactate dehydrogenase gene can itself decrease the conversion of glucose to ethanol to some extent [12], modification of the ethanol pathway, to remove competition with lactate dehydrogenase for pyruvate, has proved an effective way to increase the yield of lactic acid on glucose [2]. A single deletion of the pyruvate decarboxylase gene $P D C 1$, encoding the main PDC isoenzyme in $S$. cerevisiae, decreased PDC activity moderately but the expression of PDC5 was enhanced in the absence of PDC1 [13,14]. A double deletion of PDC1 and PDC5 in lactic acid producing $S$. cerevisiae strains decreased ethanol production and increased lactic acid yield significantly, but still some ethanol was produced because the PDC6 gene was intact [2]. In addition, the growth of the PDC1 and PDC5 deleted strain was severely reduced on glucose medium [2], which may be undesirable in a production process. In contrast, the deletion of the only pyruvate decarboxylase encoding gene, $P D C 1$, from $K$. lactis had only a mild effect on growth, was sufficient to eliminate ethanol production and improve lactate production [6].

Efficiency of lactic acid production will be affected not only by the choice of the host strain but also to some extent by the enzymatic properties of different LDH enzymes. $L D H$ genes from different organisms result in different LDH activity levels and concentrations of produced lactic acid when expressed in the same $S$. cerevisiae host strain $[4,10,15]$. LDH activity level was also affected by the copy number of the $L D H$ gene in the host [16].

We developed vectors and techniques for introducing genetic modifications into the non-conventional yeast $C$. sonorensis which enabled its genetic engineering for the first time. C. sonorensis is a methylotrophic yeast that readily ferments glucose to ethanol, utilizes several carbon sources including the pentose sugars xylose and arabinose, is relatively tolerant to acidic conditions, and has simple nutritional requirements $[17,18]$. The objective of the present work was to construct $C$. sonorensis strains expressing a heterologous $L D H$ gene and containing an intact or modified ethanol fermentation pathway, and to characterize the effects of these modifications on lactic acid production. Strains expressing the L-lactate dehydrogenase encoding genes from Lactobacillus helveticus, Bacillus megaterium, and from the fungus Rhizopus oryzae were compared and evaluated for their relative efficiency in lactate production by $C$. sonorensis. The effect of increased LDH activity level as a result of expressing multiple $L D H$ gene copies per genome was determined in strains containing a functional ethanol pathway and in strains deleted of the $P D C$ genes. These studies revealed that production of lactate, ethanol and pyruvate was determined by the PDC modifications, the choice of LDH enzyme, and the LDH enzyme activity level, which varied with the $L D H$ gene copy number.

\section{Results}

\section{Development of tools for $C$. sonorensis transformation}

Growth inhibition tests in YPD medium supplemented with antibiotics in a range of concentrations suggested that $\geq 200 \mu \mathrm{g} / \mathrm{ml}$ of G418 was inhibitory and thus could probably be used for the selection of transformants. Furthermore, $C$. sonorensis was melibiase ( $\alpha$-galactosidase) negative suggesting that transformants could be selected based on growth on the disaccharide melibiose, or screened on the chromogenic substrate X- $\alpha$-gal.

Initial attempts to transform C. sonorensis with pTEF/ Zeo, pMI203 and pMI205, containing the zeocin resistance gene expressed under heterologous promoters, did not yield selectable transformants. For this reason, a genomic library was constructed to isolate $C$. sonorensis promoters to direct the expression of $L D H$ and marker genes. Genes encoding highly expressed glycolytic phosphoglycerate kinase (PGK1) and glyceraldehyde-3-phosphate dehydrogenase $(T D H 1)$ were isolated by hybridization with the C. albicans PGK1 and the S. cerevisiae TDH1 probes, respectively. Sequences upstream of the predicted open reading frames (i.e. promoters) of the PGK1 and TDH1 genes were subsequently cloned upstream of the ORFs of the marker genes MEL5 and $\mathrm{G} 418^{\mathrm{R}}$. C. sonorensis was successfully transformed with each of the four linearized constructs using the lithium acetate method. Both the direct selection for MEL5-containing transformants on minimal medium containing melibiose as the sole carbon source and the detection of blue colour on nonselective $\mathrm{X}$ - $\alpha$-gal plates were suitable methods for the isolation of transformants. Southern analyses indicated that the integration sites varied between the transformants (data not shown).

\section{Isolation of $P D C 1$ and $P D C 2$ and demonstration of their functional roles in ethanol production}

A $0.6 \mathrm{~kb}$ fragment of a $P D C$ sequence homologue was amplified by PCR from $C$. sonorensis DNA using degenerate primers for $P D C$. The fragment was used as a probe to isolate the corresponding full length PDC1 gene (acc. AM420319) from the genomic library. Additional PCR reactions with the same degenerate $P D C$ primers revealed another putative $P D C$ sequence present in $C$. sonorensis, and a full length PDC2 gene (acc. AM420320) was 
isolated. The predicted open reading frames of the $P D C 1$ and PDC2 genes code for 575 and 568 amino acids, respectively, and have $62 \%$ amino acid sequence identity to each other, $68 \%$ and $59 \%$ identities with Ogataea parapolymorpha PDC (acc. EFW96140.1), and 61\% and 63\% identities with Candida boidinii PDC1 (acc. BAI43440), respectively, as the best hits identified in database searches (BLASTP 2.2.26). This supports the hypothesis that the two genes code for pyruvate decarboxylases.

To assess the functional role of the two $P D C$ genes, strains deleted of either one or both $P D C$ genes were constructed. C. sonorensis PDC1 was replaced by the MEL5 marker using pMI267, while PDC2 was replaced by the $G 418^{\mathrm{R}}$ marker using pMI287. Screening of transformants for decreased ethanol production enabled detection of candidate $P D C 2$-deleted strains, but candidate PDC1-deleted strains could not be distinguished. Southern analyses were used to screen for PDC1-deletion and to confirm $P D C 2$ deletion by the absence of PDC1or $P D C 2$-specific hybridization signals (Figure 1A) and the appearance of transformation marker-specific signals of appropriate size. Transformants deleted of $P D C 1$ or $P D C 2$ were found at $15 \%$ and $5 \%$ frequency, respectively.
The parent and the various $P D C$ deletion strains were grown in YP-5\% glucose and pyruvate decarboxylase enzyme activity was measured. PDC activity was similar in the wild type and $p d c 1 \Delta$ strains, but was reduced to $20 \%$ of the wild type activity or lower in the $p d c 2 \Delta$ strain. The $p d c 1 \Delta p d c 2 \Delta$ strain had essentially no detectable PDC activity (Figure 1B).

Deletion of $P D C 1$ or $P D C 2$ affected ethanol production differently. Strains with an intact $P D C 2$ produced similar amounts of ethanol irrespective of the presence or absence of PDC1 (Figure 1D). Deletion of PDC2 alone caused a large decrease in ethanol production, but deletion of both $P D C 1$ and $P D C 2$ was necessary to eliminate ethanol production (Figure 1D). These data, together with the enzyme activity measurements (Figure 1B) and Northern analyses on the expression of $C$. sonorensis $P D C 1$ and $P D C 2$ genes (data not shown) demonstrate that $P D C 2$ codes for a PDC isoenzyme that is abundant and is the main enzyme responsible for directing pyruvate to acetaldehyde and further to ethanol production.

The $p d c 1 \Delta p d c 2 \Delta$ and $p d c 2 \Delta$ strains excreted significantly more pyruvate than strains with an intact $P D C 2$ (Figure 1E). However, the $p d c 2 \Delta$ strain consumed pyruvate

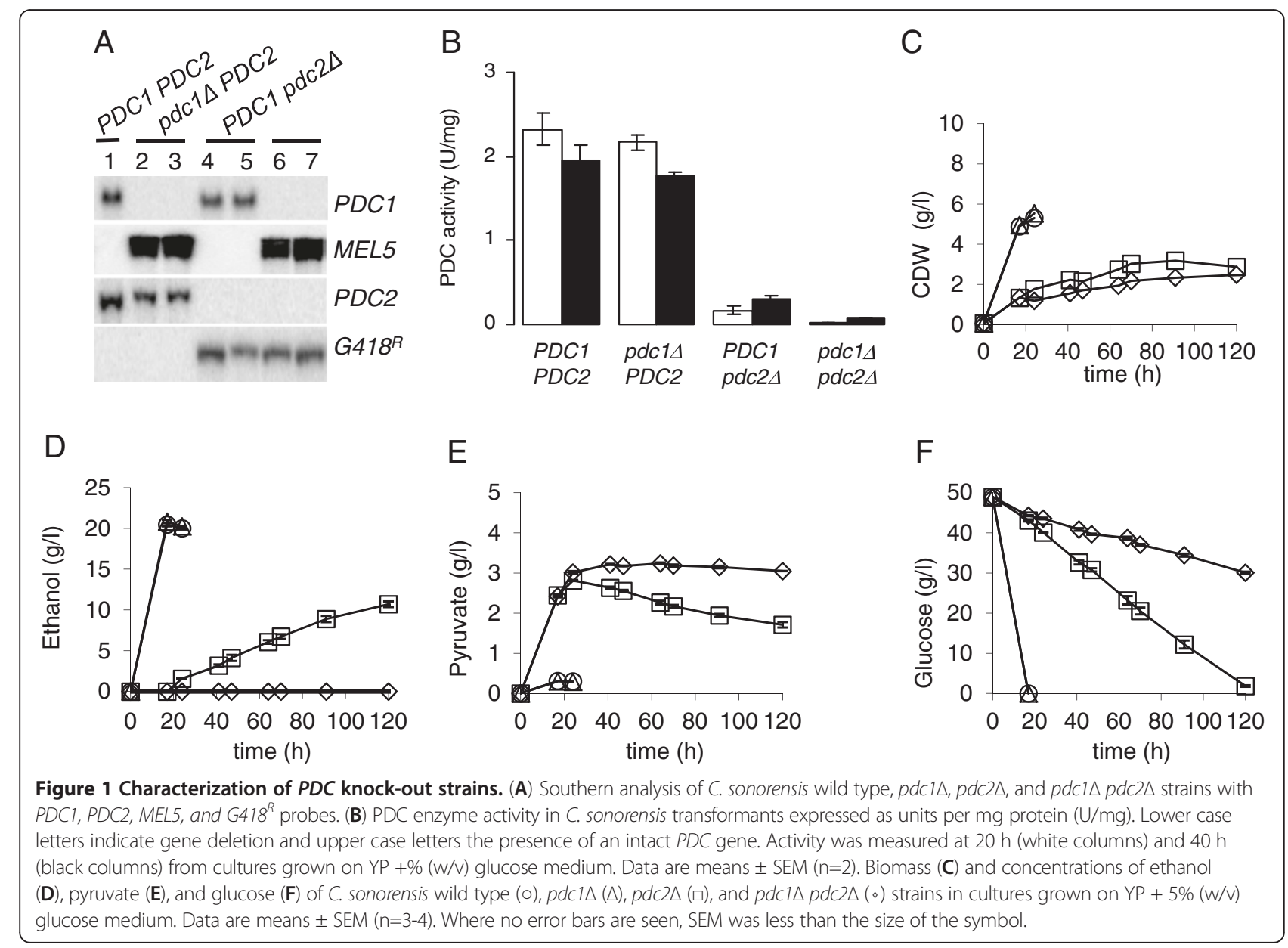


when ethanol was being produced, while no net reduction in pyruvate concentration was observed with the ethanol non-producing $p d c 1 \Delta p d c 2 \Delta$ strain.

The $p d c 1 \Delta p d c 2 \Delta$ strains utilized glucose the slowest (Figure $1 \mathrm{~F}$ ), the two strains with an intact $P D C 2$ the fastest, and $p d c 2 \Delta$ showed an intermediate glucose consumption rate. $P D C 2$ deletion also resulted in an approximately $50 \%$ decrease in the final biomass, while PDC1 deletion did not affect biomass accumulation (Figure 1C).

\section{Lactate and ethanol production with strains expressing different $L D H$ genes}

$L D H$ genes from three different sources, $L$. helveticus, $B$. megaterium and $R$. oryzae, were separately expressed in $C$. sonorensis under control of the $C$. sonorensis PGK1 promoter. Integration of the $L D H$ gene was targeted into the PDC1 locus to provide a uniform set of strains, which produce both ethanol and lactic acid, for comparison.

Strains expressing $L h L D H$ (pMI257 transformants), BmLDH (pMI265 transformants), RoLDH (pMI266 transformants) or no $L D H$ (pMI267 transformants), produced different amounts of lactate, ethanol and biomass and consumed glucose at different rates (Figure 2). The $p d c 1 \Delta:: L h L D H$ and $p d c 1 \Delta:: B m L D H$ strains produced similar lactate concentrations, whereas the $p d c 1 \Delta:: R o L D H$ strain produced significantly less lactate than the two other $L D H$ strains (Figure $2 \mathrm{~A}$ ). Ethanol was produced at the highest rate by wild type $C$. sonorensis and the $p d c 1 \Delta$ strain without $L D H$, and ethanol production by the $p d c 1 \triangle:: R o L D H$ strain was only slightly slower (Figure $2 \mathrm{~B}$ ). These strains consumed glucose at a higher rate than the $p d c 1 \Delta:: B m L D H$ and $p d c 1 \Delta:: L h L D H$ strains (Figure 2C). The $p d c 1 \triangle:: B m L D H$ strain produced ethanol and consumed glucose at higher rates than the $p d c 1 \Delta:: L h L D H$ strain (Figure 2B and C). However, they produced comparable maximum lactate and ethanol concentrations (Figure 2A and B) and final yields on glucose (Figure 2D) even though lactate yield on glucose for the $p d c 1 \Delta:$ :: $L h L D H$ strain was higher than that for the $p d c 1 \Delta:: B m L D H$ strain during the first $40 \mathrm{~h}$ of the cultivation. When lactate production per gram biomass was assessed, the $p d c 1 \Delta::$ RoLDH strain was the least and the $p d c 1 \Delta:: L h L D H$ strain the most efficient in converting glucose to lactate (data not shown). The final biomass produced by the strains lacking $L D H$ was higher $\left(\mathrm{OD}_{600}=22\right)$ than that of the $L D H$ strains, in particular when compared to the $p d c 1 \Delta:: L h L D H$ and $p d c 1 \triangle:: B m L D H$ strains $\left(\mathrm{OD}_{600}=10\right)$ (Figure $\left.2 \mathrm{D}\right)$.

\section{The effect of multiple $L D H$ gene copies on lactate and ethanol production}

Strains containing 1 to 3 copies of the $L h L D H$ or $B m L D H$ gene integrated at non-homologous sites in the genome were identified by Southern analysis (data not shown). LDH enzyme activity increased with increasing $L D H$ copy number, but the volumetric lactate production did not increase (data for $L h L D H$ shown in Figure $3 \mathrm{~A}$ and $3 \mathrm{~B}$ ). The yield of lactate on glucose did increase with increasing LDH activity and copy number (e.g. at $48 \mathrm{~h}$ $0.28,0.34$, and $0.40 \mathrm{~g}$ lactate / g glucose with 1,2 , and 3 $\mathrm{LDH}$ copies) owing to significant reduction in ethanol production, glucose consumption (Figure $3 \mathrm{C}$ and $\mathrm{D}$ ) and biomass production (data not shown).

\section{Comparison of the different $L D H$ genes in a $P D C$ negative strain background}

Representative PDC1-deleted strains, each expressing a different $L D H$ gene, or no $L D H$, were transformed with the $P D C 2$ replacement cassette from pMI287 to enable comparison of the different $L D H$ strains in the absence of PDC enzyme activity and ethanol production.

The origin of the LDHs had a greater effect on the efficiency of lactate production in the ethanol nonproducing $p d c 1 \Delta p d c 2 \Delta$ transformants (Figure 4) than in the $p d c 1 \triangle P D C 2$ transformants (Figure 3). The $p d c 1 \Delta::$ $L h L D H$ pdc2 2 strain produced 2-fold and 3-fold higher

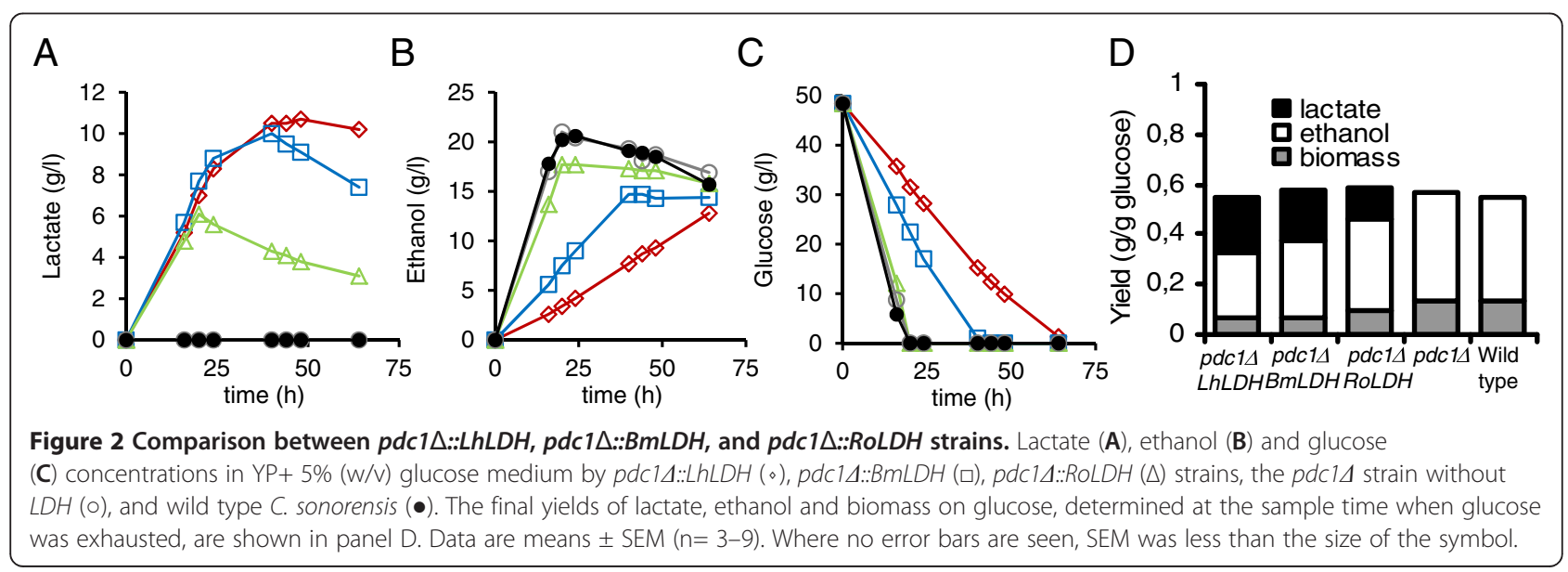



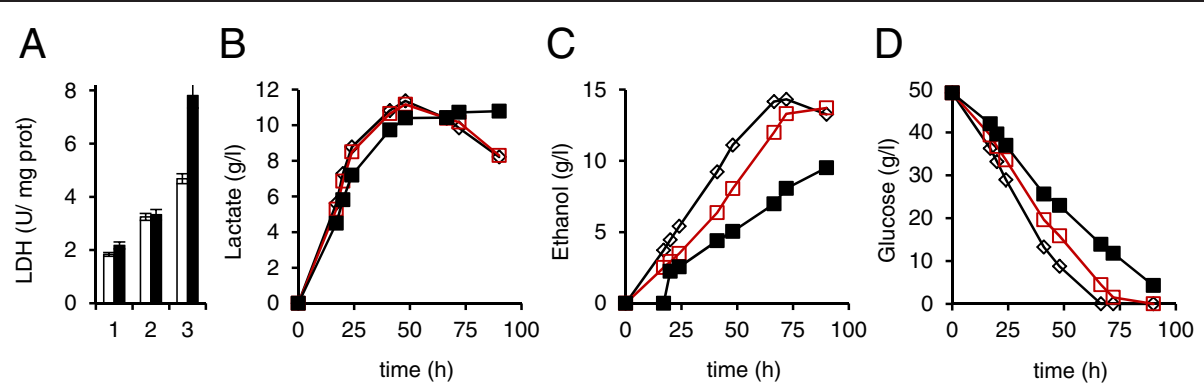

Figure 3 Effect of additional $L h L D H$ copies in PDC positive strain background. (A), LDH enzyme activity (U/mg soluble protein) after $20 \mathrm{~h}$ (white bars) and $40 \mathrm{~h}$ (black bars) cultivation, (B), lactic acid $(\mathrm{g} / \mathrm{l})$ and $(\mathbf{C})$, ethanol $(\mathrm{g} / \mathrm{l})$ production, and (D), glucose consumption $(\mathrm{g} / \mathrm{l})$ in transformants containing $1(\bullet), 2(\square)$, or $3(\mathbf{\square})$ copies of the $L h L D H$ gene integrated into unknown sites in the C. sonorensis genome. The YP+ 5\% $(w / v)$ glucose medium was initially inoculated to an $\mathrm{OD}_{600}$ of 0.1. Data are means \pm SEM $(n=2-4)$. Where no error bars are seen, SEM was less than the size of the symbol.

lactate concentrations than the $p d c 1 \triangle:: B m L D H p d c 2 \Delta$ and the $p d c 1 \Delta:: R o L D H p d c 2 \Delta$ strains, respectively (Figure $4 \mathrm{~A}$ ). Lactate contributed $92 \%(L h L D H), 72 \%(B m L D H)$ or $59 \%$ $(R o L D H)$ of the detected extracellular metabolites. All strains excreted pyruvate but the concentrations differed depending on the presence and type of LDH (Figure 4B). The highest pyruvate concentration was produced by the $p d c 1 \Delta p d c 2 \Delta$ strain without $L D H$. Of the $L D H$ strains, the
$L h L D H$ strains produced the lowest and the $R o L D H$ strains the highest pyruvate concentration (Figure 4B and D), analogous to the ethanol concentrations produced by the $p d c 1 \triangle P D C 2$ strains containing the corresponding $L D H$ gene (Figure 2B). Introduction of any of the three $L D H$ genes enhanced glucose consumption, compared with the $p d c 1 \Delta p d c 2 \Delta$ strain lacking $L D H$, the $L h L D H$ strain being the most efficient in this respect (Figure 4C).
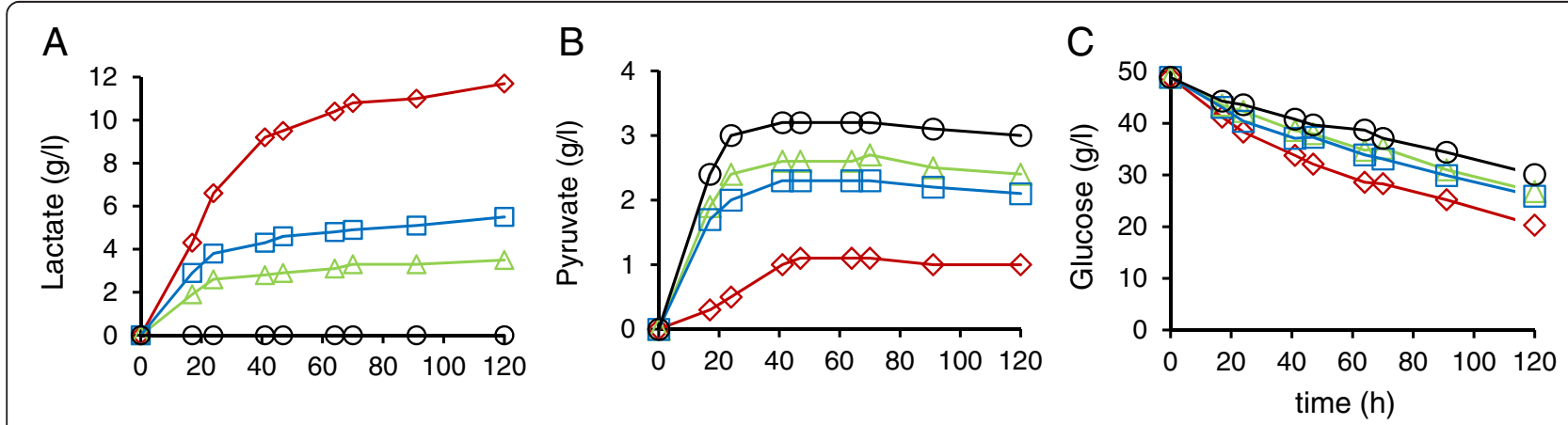

$\mathrm{D}$

$\mathrm{E}$
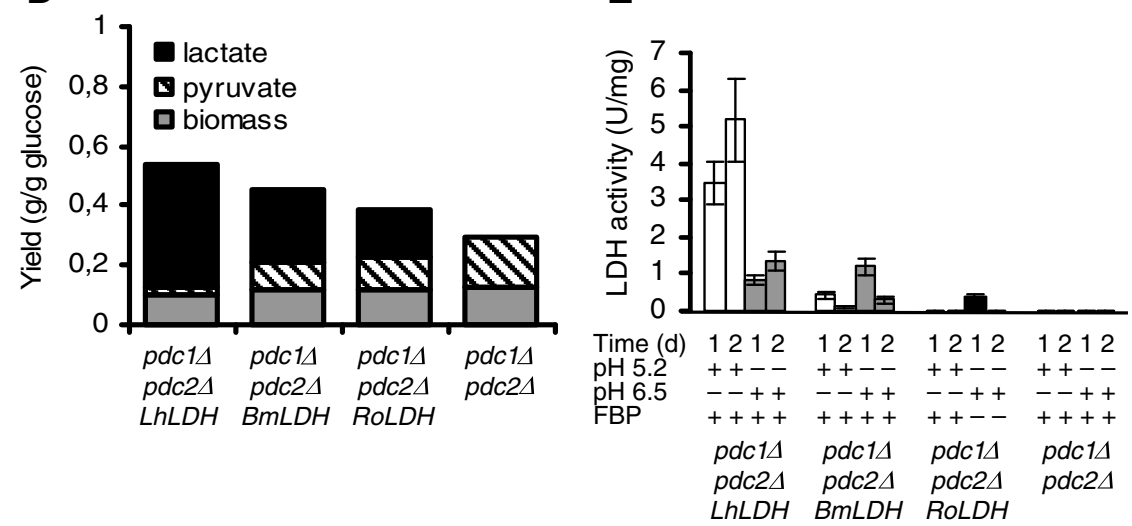

Figure 4 Comparison between $p d c 1 \Delta:: L h L D H$ pdc2 $\Delta, p d c 1 \triangle:: B m L D H$ pdc2 $\Delta$, and $p d c 1 \triangle:: R o L D H$ pdc2 $\Delta$ strains. Lactate (A), pyruvate (B) and

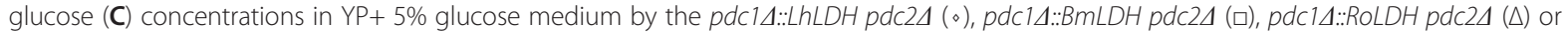
pdc1 $\Delta$ pdc2 $(\mathrm{o}, \mathrm{no} L D H)$ strains. (D). The final yields of lactate (black), pyruvate (descending diagonal) and biomass (grey) on glucose, determined at 120 h. (E). LDH enzyme activities determined at 20 h (1) and 40 h (2). FBP, 5 mM fructose-1, 6-diphosphate. Data are means \pm SEM. 
Production of lactate and pyruvate was accompanied with a decrease in the $\mathrm{pH}$ of the culture media to $\mathrm{pH} 3.3-$ 3.5 (data not shown).

LDH enzyme activities were measured with or without fructose-1,6-diphosphate at two different $\mathrm{pH}$ values due to the differences in the optimal conditions for the individual enzymes $[19,20]$. The LDH enzyme activity measured in vitro in the $P D C$ negative strains containing one copy of $L h L D H, B m L D H$ or $R o L D H$ directly correlated with the lactate amount measured; the $L h L D H$ strain that produced the highest final lactate concentration also had the highest enzyme activity (Figure 4E).

Addition of a second $B m L D H$ copy, integrated in the PDC2 locus, increased the final lactate concentration by $30 \%$ (Figure 5 ), reduced pyruvate accumulation by $15 \%$, and enhanced glucose consumption compared to the single copy $B m L D H$ strain. Based on these data it appears that the level of BmLDH enzyme activity in the single copy $B m L D H$ strain restricted lactate production. In comparison, a second copy of $L h L D H$ resulted in small $(<9 \%)$ but significant increase in lactate (Figure 5) and decrease in pyruvate production (not shown). Even so, cessation of lactate production still occurred and was not overcome by increasing $L D H$ copy number, which suggests that factors other than $\mathrm{LDH}$ dosage prevented lactate accumulation in the $C$. sonorensis cultures.

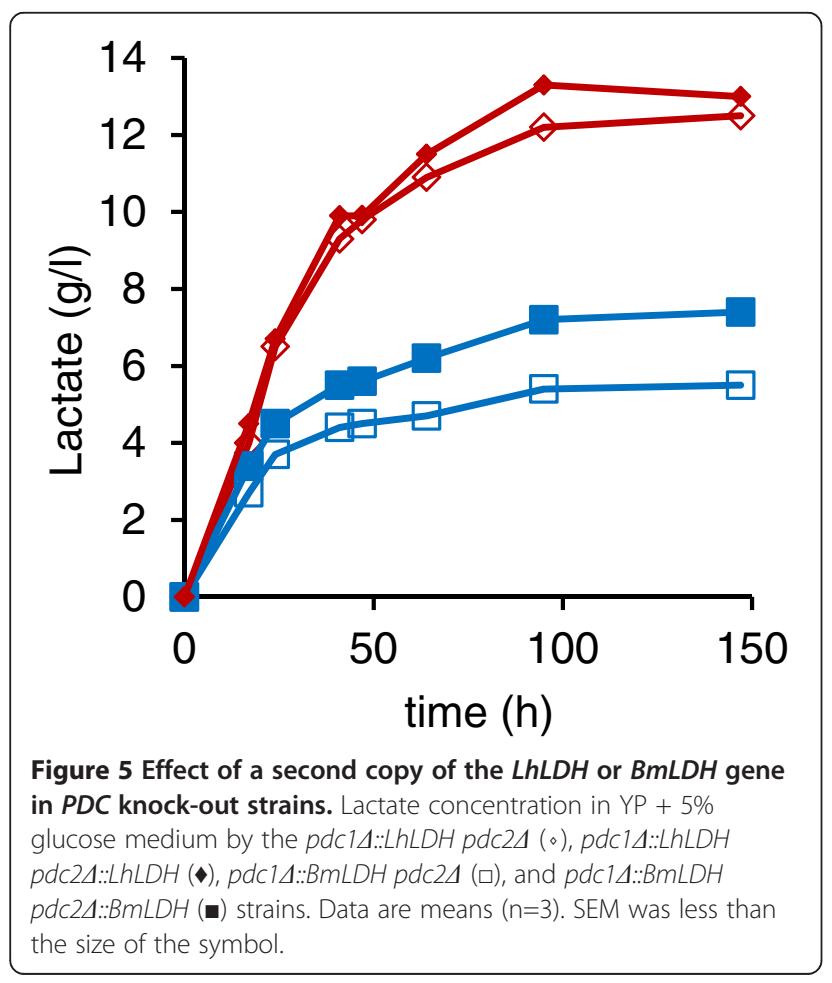

The correlation to lactate concentration of the concentration of $\mathrm{CaCO}_{3}$ added as a neutralizing agent In the previous experiments less than $14 \mathrm{~g} / \mathrm{l}$ lactate was produced in medium with no $\mathrm{pH}$ buffering (final $\mathrm{pH} 3.3)$. The $p d c 1 \Delta:: L h L D H$ pdc $2 \Delta:: L h L D H$ strain, was also grown in YP-10\% glucose medium supplemented with calcium carbonate $\left(\mathrm{CaCO}_{3}\right)$ concentrations from 5 to $30 \mathrm{~g} / \mathrm{l}$ as a neutralizing agent to control the $\mathrm{pH}$ and to determine the relationship between free lactic acid and total lactate production. The final $\mathrm{pH}$ in the cultures was between $\mathrm{pH} 3.5$ and 4 (Figure 6A), around the pKa of lactic acid ( $\mathrm{pH} 3.8)$. The total lactate concentration (24 to $66 \mathrm{~g} / \mathrm{l}$ ), lactate yield on glucose, and final $\mathrm{pH}$ increased with increasing $\mathrm{CaCO}_{3}$ concentration, but the concentration of free lactic acid varied relatively little between the conditions and was maximal, $19 \mathrm{~g} / \mathrm{l}$, at low $\mathrm{CaCO}_{3}$ concentrations (Figure 6A). The proportion of free lactic acid in the total lactate decreased with increasing $\mathrm{CaCO}_{3}$ concentration and final $\mathrm{pH}$ from $\sim 80 \%$

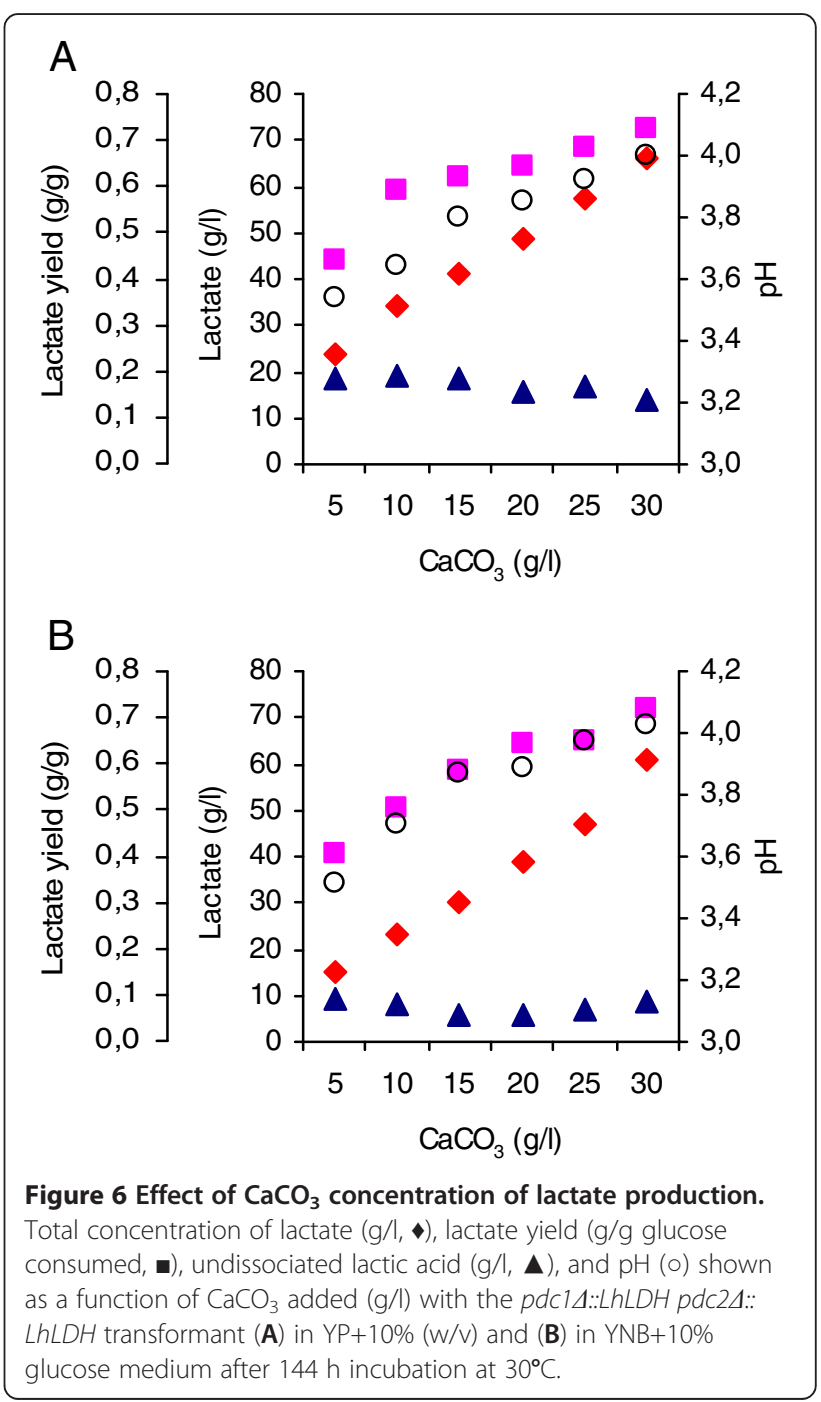


Table 1 Extracellular metabolites produced in the presence of $\mathrm{CaCO}_{3}$

\begin{tabular}{|c|c|c|c|c|}
\hline Strain & Lactate $(\mathrm{g} / \mathrm{l})$ & Yield of lactate $(\mathrm{g} / \mathrm{g})$ & Ethanol $(g / l)$ & Pyruvate $(g / l)$ \\
\hline$x:: B m L D H$ & $85 \pm 1.7$ & $0.89 \pm 0.02$ & $\leq 0.3$ & $\leq 0.2$ \\
\hline $\operatorname{pdc} 1 \triangle: B m L D H$ & $88 \pm 1.4$ & $0.90 \pm 0.01$ & $1.3 \pm 0.4$ & $\leq 0.5$ \\
\hline$p d c 2 \triangle \because B m L D H$ & $84 \pm 2.6$ & $0.87 \pm 0.02$ & $1.2 \pm 0.6$ & $\leq 0.6$ \\
\hline$p d c 1 \triangle: B m L D H$ pdc2 $\triangle$ & $84 \pm 2.9$ & $0.85 \pm 0.03$ & n.d. & $2.1 \pm 0.3$ \\
\hline$p d c 1 \triangle * B m L D H$ pdc2 $2 \triangle: B m L D H$ & $81 \pm 3.2$ & $0.80 \pm 0.03$ & n.d. & $0.79 \pm 0.02$ \\
\hline$x:: L h L D H$ & $83 \pm 1.7$ & $0.85 \pm 0.02$ & $\leq 0.3$ & n.a. \\
\hline pdc1 $\triangle:: L h L D H$ & $93 \pm 0.8$ & $0.95 \pm 0.01$ & $1.3 \pm 0.3$ & $\leq 0.5$ \\
\hline$p d c 1 \triangle: L h L D H$ pdc2 $\triangle$ & $92 \pm 1.6$ & $0.94 \pm 0.02$ & n.d. & $0.72 \pm 0.13$ \\
\hline 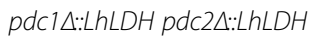 & $86 \pm 1.3$ & $0.88 \pm 0.02$ & n.d. & $0.39 \pm 0.08$ \\
\hline$x:: R O L D H$ & $78 \pm 1.5$ & $0.81 \pm 0.02$ & $3.2 \pm 0.2$ & n.a. \\
\hline pdcl $\triangle: R o L D H$ & $75 \pm 0.6$ & $0.77 \pm 0.02$ & $7.0 \pm 1.2$ & $<0.5$ \\
\hline$p d c 1 \triangle: R o L D H$ pdc2 $\Delta$ & $78 \pm 0.2$ & $0.81 \pm 0.01$ & n.d. & $3.2 \pm 0.3$ \\
\hline wild type C. sonorensis & n.d. & n.d. & $17 \pm 5.3$ & n.a. \\
\hline
\end{tabular}

Maximum concentrations of lactate, ethanol and pyruvate $(\mathrm{g} / \mathrm{l})$ and lactate yield on glucose $(\mathrm{g} / \mathrm{g})$ produced in YNB-10\% (w/v) glucose minimal medium containing non-limiting concentration of $\mathrm{CaCO}_{3}$. Results are from 6 experiments, each with 4-6 strains. Data are means \pm SEM ( $\left.n=3-10\right)$. n.a. not analyzed. n.d. not detected.

at final $\mathrm{pH} 3.5$ to $\sim 20 \%$ at final $\mathrm{pH}$ 4. A similar correlation between $\mathrm{CaCO}_{3}$ and lactate concentrations was also observed on YNB-10\% glucose medium (Figure 6 B) but the lactate concentration was $10 \mathrm{~g} / \mathrm{l}$ higher in rich YP medium than in YNB-medium at each $\mathrm{CaCO}_{3}$ concentration between 5 and $25 \mathrm{~g} / \mathrm{l}$ (Figure 6). The $\mathrm{pH}$ in YP and YNB media were similar at each $\mathrm{CaCO}_{3}$ concentration although the lactate concentrations differed.

\section{Lactate production in cultivations containing a non- limiting concentration of $\mathrm{CaCO}_{3}$}

$L h L D H, B m L D H$ and $R o L D H$ strains, with and without $P D C$ modifications, were studied for lactate production on YNB-10\% glucose minimal medium using a twostage cultivation protocol with separate biomass generation and lactate production phases. The production phase was inoculated with a biomass concentration of $5 \mathrm{~g} / \mathrm{l}$ cell dry weight and the $\mathrm{pH}$ was maintained above 5.7 by addition of $\mathrm{CaCO}_{3}$.

The $L h L D H, B m L D H$ and $R o L D H$ strains produced up to 93,88 and $78 \mathrm{~g} / \mathrm{l}$ lactate, respectively (Table 1$)$. Glucose consumption and lactate production for representative $p d c 1 \Delta:: L D H$ pdc2 $\triangle$ are shown in Figure 7 . The lactate production rate during the first 24 hours was the highest with the $p d c 1 \Delta:: L h L D H$ pdc $2 \Delta$ strain $(3.3 \mathrm{~g} / \mathrm{l} / \mathrm{h})$ followed by the pdc1 $1:: B m L D H$ pdc2 $2.0 \mathrm{~g} / \mathrm{l} / \mathrm{h})$ and $p d c 1 \Delta:: R o L D H$ $p d c 2 \Delta(1.5 \mathrm{~g} / \mathrm{l} / \mathrm{h})$. A visible calcium lactate precipitate was formed in some cultivations of the $L h L D H$ or $B m L D H$ strain, but was never formed in the $R o L D H$ cultivations. The $L h L D H$ strains produced on average $5 \mathrm{~g} / \mathrm{l}$ more lactate than the corresponding $B m L D H$ strains when the PDC1 gene or both $P D C$ genes were deleted, but the difference was not statistically significant. The optical purity of the lactate was high, since the concentration of D- lactate was below $0.6 \mathrm{~g} / \mathrm{l}$ (determined enzymatically from samples containing the maximum lactate concentration). Thus more than $99 \%$ of the total lactate was L-lactate.

The ethanol concentrations were small even for the strains with intact PDC1 and/or PDC2 (Table 1) in YNB$10 \%$ glucose medium with $\mathrm{CaCO}_{3}$. The $\mathrm{RoLDH}$ strains with an intact $P D C 2$ produced significantly $(\mathrm{p}<0.05)$ more ethanol than the $L h L D H$ or $B m L D H$ strains with an intact PDC2 (Table 1).

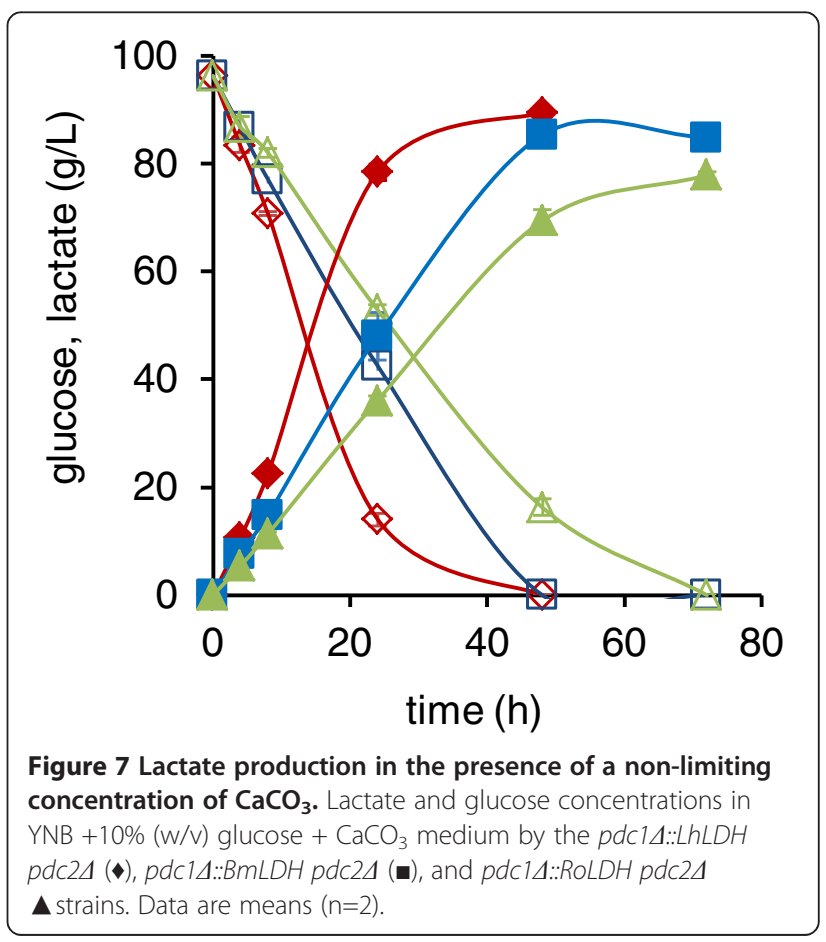


Pyruvate concentrations produced by the pdc1 $1:: L D H$ $p d c 2 \Delta$ strains were significantly different $(\mathrm{p}<0.05)$ for $L h L D H, B m L D H$, and $R o L D H$ strains. The pyruvate concentration was also lower for the strains containing two copies of $B m L D H$ or $L h L D H$ than for the corresponding strains with a single $L D H$ gene copy (Table 1 ), as in the non-buffered cultivations (see above).

In the absence of both PDC genes no ethanol was produced. As the by-product concentrations for all strains were extremely small relative to lactate concentrations, and decrease in ethanol concentration was accompanied with an increase in pyruvate concentration, double $P D C$ deletions did not result in an increase in lactate concentration or yield on glucose.

\section{Intracellular lactate and pyruvate concentrations}

Intracellular and extracellular lactate concentrations were correlated in $P D C$ positive $B m L D H$ strains cultivated in $\mathrm{CaCO}_{3}$-buffered minimal media. Cells in $\mathrm{CaCO}_{3}$-buffered medium had more intracellular lactate compared to extracellular lactate at the beginning of the cultivations ( 0 and 8 hours). At the end of cultivation (48 hours) the intra- and extracellular lactate concentrations were similar (up to $80 \mathrm{~g} / \mathrm{l}$ ) (Figure 8A).

The intracellular pyruvate concentration was higher in $p d c 1 \Delta p d c 2 \Delta$ strains than in strains containing an intact PDC2 (pdc1 1 PDC2 or PDC1 PDC2), as was the extracellular concentration (Figure $8 \mathrm{~B}$ ).

\section{Discussion}

New molecular tools have enabled genetic engineering of $C$. sonorensis for the first time. The antibiotic marker gene $\mathrm{G} 418^{\mathrm{R}}$ and the non-antibiotic marker MEL5 were expressed under the control of endogenous $P G K 1$ or $T D H 1$ promoters, and the $P G K 1$ promoter was additionally used to express three different $L D H$ genes. Targeted integration into $P D C 1$ and $P D C 2$ through homologous recombination was common but not as frequent as integration into non-homologous sites in the genome. In addition to $P D C$ loci, homologous integration into the PGK1 locus occurred in some transformants when the marker gene was located between two identical $P G K 1$ promoter copies in the construct, e.g. in pMI257 or pMI265.

C. sonorensis has two non-allelic PDC genes, PDC1 and $P D C 2$, both of which contribute to ethanol production. The $P D C 2$ gene encodes the major isoenzyme. $P D C 2$ deletion resulted in a decrease in growth, glucose utilization and ethanol production rates, and in an increase in pyruvate levels. In contrast, the PDC1 deleted strain did not noticeably differ from the parent strain in respect to these parameters, and $85 \%$ of PDC activity was retained. Both intra- and extracellular pyruvate concentrations were significantly increased in the $C$. sonorensis $p d c 1 \Delta p d c 2 \Delta$ strain, compared with strains containing an intact $P D C 2$ gene. The expression of any of the three $L D H$ genes in the $C$. sonorensis pdc1 $\Delta$ pdc2 $\Delta$ strain background provided an alternative route for pyruvate metabolism and $\mathrm{NAD}^{+}$regeneration, and was accompanied with a significant decrease in pyruvate accumulation, particularly in the $L h L D H$ strain. $L D H$ expression in a $p d c 1 \Delta p d c 2 \Delta$ strain also enhanced glucose consumption in non-buffered medium, with LhLDH having a greater positive effect than the other two LDHs had. Even so, glucose consumption by a $p d c 1 \Delta:: L h L D H p d c 2 \Delta$ strain was slow relative to the ethanol producing $L D H$ strains in non-buffered medium, as also observed in S. cerevisiae [2].

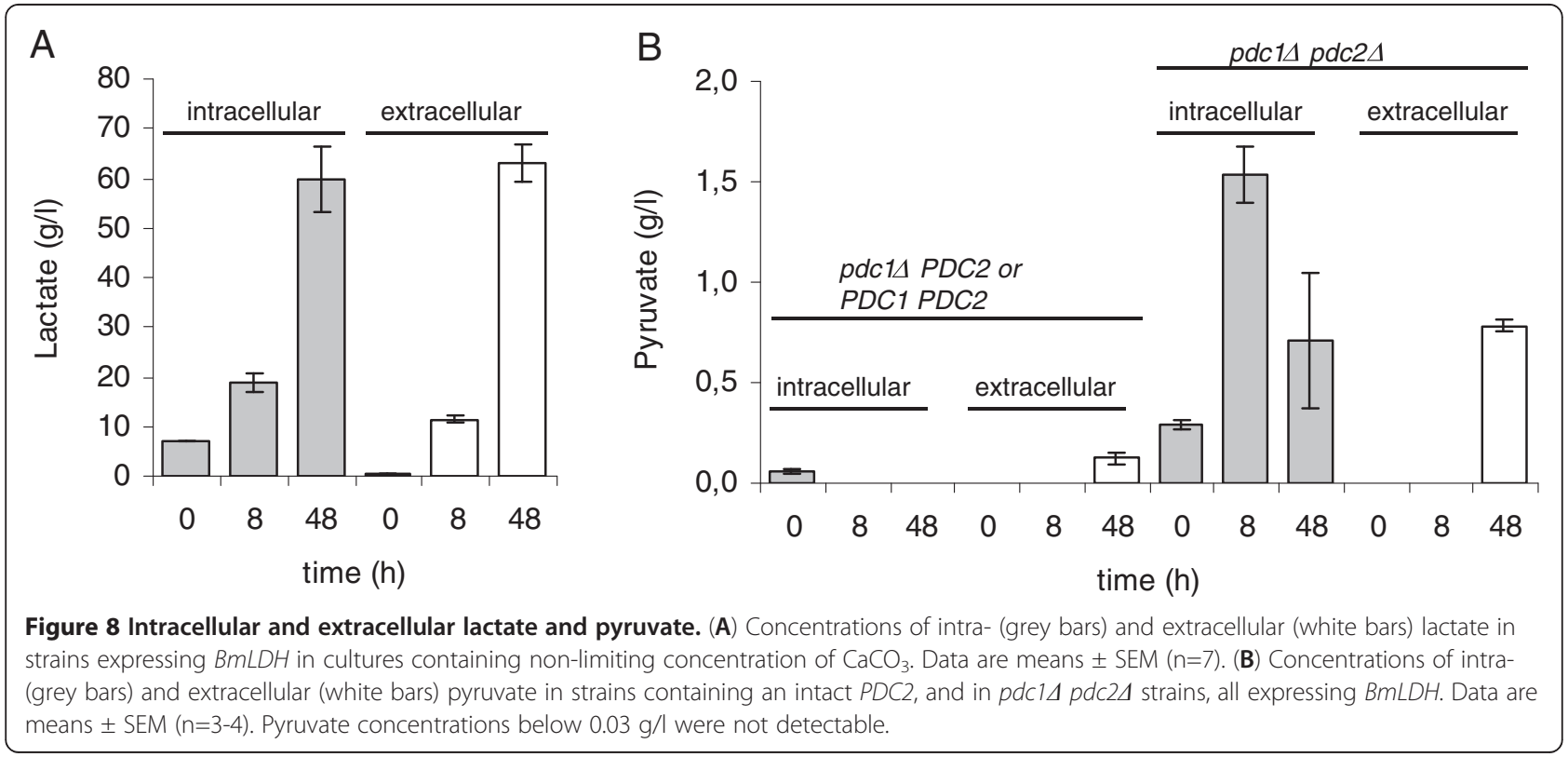


C. sonorensis strains expressing $L D H$ from $L$. helveticus, $B$. megaterium or $R$. oryzae, showed characteristic differences in the conversion of glucose to lactate and byproducts, demonstrating that the properties of the LDH enzyme have a fundamental impact on carbon distribution at the pyruvate branch point. In general, the concentration and yield on glucose of the by-products ethanol $(\mathrm{PDC}+)$ or pyruvate $(p d c 1 \Delta p d c 2 \Delta)$ were the highest with the RoLDH strains and the lowest with the $L h L D H$ strains. The efficiency of lactate production corresponded to the LDH enzyme activity, with the $L h L D H$ strain having the highest, the $B m L D H$ strain intermediate, and the $R o L D H$ strain the lowest in vitro activity in single-copy $L D H$ strains. S. cerevisiae strains expressing a LDH from Lactobacilli had higher LDH activity than a $B m L D H$ expressing strain [15]. Data on the properties of the LDH enzymes used are limited, but significant differences have been reported $[15,19,20]$. The kinetic properties such as the $\mathrm{pH}$ optimum, affinity for pyruvate and the cofactor $\mathrm{NADH}$, inhibition by a high substrate or product concentration, and the equilibrium of the reaction would determine the effectiveness of each enzyme in vivo. Indeed, the $C$. sonorensis strains with different LDH enzymes produced different final extracellular lactate and pyruvate concentrations, which were shown to correlate with intracellular concentrations.

Concentrations of intracellular lactate have not been reported for $L D H$ expressing yeasts to date. The present initial work found that lactic acid producing $C$. sonorensis cells harvested from un-buffered cultures contained a significant intracellular lactic acid concentration. This may interfere with multiple cellular functions, but in spite of this, the cells were able to excrete lactate. It has been proposed that lactate export is energy dependent and uses ATP in S. cerevisiae [21]. The lactate and acetate transporters JEN1 and ADY2 that are known to import lactate are also involved in lactate excretion, but another presently unknown lactate export mechanism also exists in S. cerevisiae [22,23].

Lactic acid accumulation decreases the $\mathrm{pH}$ of the culture medium leading to an increase in the proportion of undissociated lactic acid in the medium. At pH 4, a fraction of the lactic acid will be undissociated. Undissociated acid is believed to re-enter the cell also via passive diffusion. In the cytosol, at neutral $\mathrm{pH}$, it will dissociate to form the lactate anion and proton, thus increasing the ATP demand for lactate export [21]. Cytosolic acidification caused by lactic acid may eventually result in cell death [24].

Lactic acid accumulation causes also weak acid stress to the cells. Cells exposed to weak acids adapt to some extent, for instance by up-regulating excretion of the acid, by blocking re-entry, or by metabolizing the acid [25]. Different yeast species may use different strategies to maintain cellular $\mathrm{pH}$ and ion homeostasis. The present data showed that lactate concentration in the culture medium decreased in prolonged cultivations indicating that the cells consumed lactate (see e.g. Figure 2).

An optimal lactic acid production host should tolerate acidic conditions and produce a high concentration of undissociated lactic acid in order to reduce the need for neutralizing chemicals, and ethanol production should be eliminated. As shown in Figure 6, the media composition (YP or YNB) and the amount of $\mathrm{CaCO}_{3}$ determine how much lactic acid a strain can produce. The medium composition is an important consideration in production process because of cost, downstream processing, and product quality, which was why minimal medium (YNB) was mainly used in the present work. It is evident that differences in the culture conditions used by different groups complicate fair comparison between the species. Not surprisingly, the highest total lactate production levels by yeasts have been obtained at higher $\mathrm{pH}$ using non-limiting concentration of neutralizing chemicals.

When benchmarked against published results where media and operating conditions are disclosed, this $C$. sonorensis strain compares favorably. Representative results for lactate producing yeast strains, which produce little or no ethanol, at neutral $\mathrm{pH}$ have been reported for C. boidinii that produced $86 \mathrm{~g} / \mathrm{l}$ lactic acid in the presence of non-limiting $\mathrm{CaCO}_{3}$ and final pH 6.15 [8], and C. sonorensis that produced $92 \mathrm{~g} / \mathrm{l}$ lactate at $0.94 \mathrm{~g} / \mathrm{g}$ yield on glucose in less than $48 \mathrm{~h}$. S. cerevisiae pdc1 1 pdc5 $\Delta$ strain produced $82 \mathrm{~g} / \mathrm{l}$ lactate at $0.82 \mathrm{~g} / \mathrm{g}$ yield in YP-10\% glucose in the presence of $30 \mathrm{~g} / \mathrm{l} \mathrm{CaCO}_{3}$, but the $\mathrm{pH}$ was not reported [2]. C. utilis produced $103 \mathrm{~g} / \mathrm{l}$ lactic acid in YP medium containing $109 \mathrm{~g} / \mathrm{l}$ glucose $\left(0.95 \mathrm{~g} / \mathrm{g}\right.$ yield on glucose) and $45 \mathrm{~g} / \mathrm{l} \mathrm{CaCO}_{3}$ in in $33 \mathrm{~h}$, with final $\mathrm{pH}$ of 4 [9]. S. cerevisiae wine yeast produced $40 \mathrm{~g} / \mathrm{l}$ lactate [3], and diploid S. cerevisiae produced $50 \mathrm{~g} / \mathrm{l}$ lactate below pH 4 [14]. C. boidinii produced $50 \mathrm{~g} / \mathrm{l}$ lactic acid in YP-10 g/l glucose medium containing $30 \mathrm{~g} / \mathrm{l}$ $\mathrm{CaCO}_{3}$. In comparison, C. sonorensis $\mathrm{LhLDH}$ strains produced in YP medium $66 \mathrm{~g} / \mathrm{l}$ lactate $(0.73 \mathrm{~g} / \mathrm{g}$ yield $)$ with $30 \mathrm{~g} / \mathrm{L}$ of $\mathrm{CaCO}_{3}$ and final $\mathrm{pH}$ 4.0. The LDH and PDC modifications are the necessary basis for further yeast development towards an industrial lactic acid process.

\section{Conclusions}

We developed an organism without previous record of genetic engineering to efficiently produce L-lactic. Genetic modification of $C$. sonorensis opens the possibility to exploit this novel host organism in the production of useful biochemicals. The frequent occurrence of both targeted and non-homologous integration into the genome gives flexibility to strain design and construction. Both PDC1 and PDC2 enzymes contributed to ethanol production, but $P D C 2$ encodes the main isoenzyme. The 
possibility to generate knock out strains allowed us to demonstrate the significance of each of the $P D C$ genes in the context of lactic acid production in C. sonorensis. Unexpectedly, $L D H$ strains with intact $P D C$ genes produced very little ethanol and as much lactate as the $P D C$ deleted strains in the presence of $\mathrm{CaCO}_{3}$, although the same strains produced more ethanol than lactate in nonbuffered conditions. This indicated that not only the genotype but also the culture conditions had a large influence on carbon distribution between ethanol and lactate.

The Cargill commercial implementation of a yeast for lactic acid production has demonstrated the high potential of yeasts as hosts for organic acid production [26]. This present work showed that glucose could be converted to highly pure L-lactate at an excellent yield by $C$. sonorensis expressing a $L D H$ in minimal medium in the presence of $\mathrm{CaCO}_{3}$. The purity of the product i.e. taking into account the formation of by-products ethanol and pyruvate, and to some extent the concentration of lactate differed between strains expressing different $L D H$ genes. The lactate production parameters (concentration, yield, production rate) observed with $C$. sonorensis strains expressing $L h L D H$ compare favorably with other lactic acid producing yeasts, illustrating that Candida yeasts have high potential as lactic acid production hosts. Among the $L D H$ genes studied, $L h L D H$ was the most suitable one to produce lactic acid with $C$. sonorensis in the conditions studied. Thus, the choice of the LDH is an important consideration in the development of improved production hosts.

\section{Methods}

\section{Microbial strains}

E. coli strains DH5 $\alpha$ (Gibco BRL, Gaithersburg, MD) and XL-1 Blue (Stratagene, La Jolla, CA) were used as hosts for cloning and plasmid propagation. C. sonorensis ATCC32109 (American Type Culture Collection), was used throughout the study and was the parental strain of the transformants generated in this work.

\section{Media and cultivation conditions}

C. sonorensis was maintained on agar solidified $1 \%(\mathrm{w} / \mathrm{v})$ yeast extract $-2 \%(\mathrm{w} / \mathrm{v})$ Bacto peptone $-2 \%(\mathrm{w} / \mathrm{v})$ glucose (YPD) medium supplemented with $200 \mathrm{mg} / \mathrm{l}$ geneticin (G-418 sulfate; Invitrogen, Carlsbad, CA, USA) or $40 \mathrm{mg} / \mathrm{l}$ 5-bromo-4-chloro-3-indolyl- $\alpha$-D-galactopyranoside (X- $\alpha$ Gal; ICN Biochemicals, Aurora, OH, USA), as appropriate. Test tube cultivations were carried out in $5 \mathrm{ml} 1 \%(\mathrm{w} / \mathrm{v})$ yeast extract $-2 \%(\mathrm{w} / \mathrm{v})$ peptone medium (YP) containing $5 \%(\mathrm{w} / \mathrm{v})$ glucose for initial tests for lactate and ethanol production and were incubated at $250 \mathrm{rpm}$.

Non-buffered cultivations in YP - 5\% (w/v) glucose were inoculated to an optical density $\left(\mathrm{OD}_{600}\right)$ of 0.2 with cells grown on YPD agar. In some experiments the YP medium contained $10 \%(\mathrm{w} / \mathrm{v})$ glucose and 5 to $30 \mathrm{~g} / \mathrm{l}$ of calcium carbonate $\left(\mathrm{CaCO}_{3}\right)$ for $\mathrm{pH}$ control.

For two-stage cultivations, the biomass was grown in yeast nitrogen base medium (YNB w/o amino acids; Difco, Sparks, MD) supplemented with $5 \%$ glucose and buffered to $\mathrm{pH} 5.5$ with $0.5 \mathrm{M}$ 2-[N-Morpholino] ethanesulfonic acid (MES). After overnight cultivation at $30^{\circ} \mathrm{C}$ and $250 \mathrm{rpm}$, cells were harvested by centrifugation and transferred into YNB medium supplemented with $10 \%(\mathrm{w} / \mathrm{v})$ glucose, to give an initial cell density of $\mathrm{OD}_{600} \sim 15$ corresponding to approximately $5 \mathrm{~g} / \mathrm{l}$ cell dry weight. $80 \mathrm{~g} / \mathrm{l}$ of calcium carbonate was added for $\mathrm{pH}$ control in some of the cultures.

Cultures were incubated at $30^{\circ} \mathrm{C}$ with $100 \mathrm{rpm}$ shaking in $250 \mathrm{ml}$ Erlenmeyer flasks containing $50 \mathrm{ml}$ medium.

\section{DNA manipulations}

Plasmid DNA was isolated using Qiagen kits (Qiagen Corp, Chatsworth, CA, USA). Recombinant DNA work was carried out using conventional techniques [27]. Oligonucleotides were purchased from Sigma-Genosys (Little Chalfont, UK). PCR was performed using Dynazyme EXT polymerase (Finnzymes, Espoo, Finland) with an initial incubation for $3 \mathrm{~min}$ at $94^{\circ} \mathrm{C}$, followed by 29 cycles of $45 \mathrm{sec}$ at $94^{\circ} \mathrm{C}, 45 \mathrm{sec}$ at $55^{\circ} \mathrm{C}, 2 \mathrm{~min}$ at $72^{\circ} \mathrm{C}$, with a final incubation for $10 \mathrm{~min}$ at $72^{\circ} \mathrm{C}$.

\section{Isolation of PGK1, TDH1, PDC1 and PDC2 genes from $C$. sonorensis}

Yeast DNA was isolated by phenol extraction from cells broken with glass beads [28]. The genomic library of $C$. sonorensis ATCC32109 was prepared using partially Sau3A digested size fractionated genomic DNA that was cloned into the BamHI digested lambda $\mathrm{DASH}^{\mathrm{Tm}}$ vector (Stratagene, La Jolla, CA, USA) as described previously [29]. The library was screened by colony/plaque hybridization. $C$. albicans PGK1, amplified by PCR from genomic DNA with primers 5092 and 5091 was used as a probe to isolate the C. sonorensis gene for 3-phosphoglycerate kinase (PGK), and S. cerevisiae TDH1, amplified with primers 4125 and 4126 (Table 2) was used as a probe to isolate the gene for glyceraldehyde-3-phosphate dehydrogenase (GAPDH). Fragments of PDC1 and PDC2, were amplified from genomic DNA of C. sonorensis with primers 5116 and 5118 (Table 2) which were designed from conserved regions in the known pyruvate decarboxylase amino acid sequences, WAGNANELNA and DFNTGSFSY, of P. stipitis PDC1 (U75310) and PDC2 (U75311), S. cerevisiae PDC1 (X04675), and C. albicans PDC11 and PDC12 (sequence data for C. albicans was obtained from the Candida Genome Database website at http://www.candidagenome.org/). The C. sonorensis PDC1 and PDC2 fragments obtained with primers 5116 and 5118 (Table 2) were used as probes 
Table 2 Oligonucleotides used in this work

\begin{tabular}{|c|c|c|}
\hline Name & Sequence & Description \\
\hline 4125 & $5^{\prime}$-tgtcatcactgctccatctt-3' & S. cerevisiae TDH1 gene \\
\hline 4126 & 5'-ttaagccttggcaacatatt-3' & S. cerevisiae TDH1 gene \\
\hline 5092 & 5'-gcgatctcgaggtcctagaatatgtatactaatttgc-3' & C. albicans PGK1 ORF (acc. U25180) \\
\hline 5091 & 5'-cgcgaattcccatggttagtttttgttggaaagagcaac-3' & C. albicans PGK1 ORF (acc. U25180) \\
\hline 5423 & 5'-gcgatctcgagaaagaaacgacccatccaagtgatg-3' & CSPGK1 promoter -1500 \\
\hline 5439 & 5'-tggactagtacatgcatgcggtgagaaagtagaaagcaaacattgtatatagtcttttctattattag-3' & CSPGK1 promoter-MEL5 fusion \\
\hline 5441 & 5'-gcgatctcgagaaaatgttattataacactacac-3' & CSTDH1 promoter -600 \\
\hline 5440 & 5'-tggactagtacatgcatgcggtgagaaagtagaaagcaaacattttgtttgatttgtttgttttgtttttgtttg-3' & CSTDH1 promoter MEL5 fusion \\
\hline 5427 & 5'-acttggccatggtatatagtcttttctattattag-3' & CsPGK1 promoter - LhLDH fusion \\
\hline LhLDH1 & 5'-atggcaagagaggaaaaacctcgtaaag-3' & $L h L D H$ probe (fwd) \\
\hline LhLDH2 & 5'-ccacgaagagtcattgacgaaccttaa-3' & LhLDH probe (rev) \\
\hline $\mathrm{BmLDH} 1$ & 5'-ccaacaaaaccagttccgataacg-3' & $B m L D H$ probe (fwd) \\
\hline ScerGal10t & 5'-ccggactagttggtacagagaacttgtaaacaattcgg-3' & $B m L D H$ probe (rev) \\
\hline RoLDHA1 & 5'-ctagctcagaacaatggtattacactcaaaggtcgccatcg-3' & RoLDH probe (fwd) \\
\hline RoLDHA2 & 5'-cgcggatccgaattctcaacagctacttttagaaaaggaag-3' & RoLDH probe (rev) \\
\hline 5116 & 5'-ccggaattcgatatctgggcwggkaatgccaaygarttraatgc-3' & $P D C 1$ and $P D C 2$ probes (fwd) \\
\hline 5118 & 5'-cgcggattcaggectcagtangaraawgaaccngtrttraartc-3' & $P D C 1$ and $P D C 2$ probes (rev) \\
\hline G418-5' & 5'-ctagtctagaacaatgagccatattcaacgggaaacg-3' & G418 probe (fwd) \\
\hline G418-3' & $5^{\prime}$-cgcggatccgaattcttagaaaaactcatcgag catcaaatg-3' & G418 $8^{R}$ probe $(r e v)$ \\
\hline Cs1 & $5^{\prime}$-ctagtctagatttgtttgatttgtttgttttgttttgtttg-3' & C. sonorensis $\mathrm{TDH} 1$ promoter \\
\hline Cs2 & 5'-ctagtctagatgtatatagtcttttctattattag-3' & C. sonorensis PGK1 promoter \\
\hline $\operatorname{Cs} 5$ & 5'-ggcccgcggccgctacaagtgattcattcattcact-3' & C. sonorensis PDC1 $5^{\prime}$ flank \\
\hline Cs6 & 5'-ccctgggeccctcgaggatgatttagcaagaataaattaaaatgg-3' & C. sonorensis PDC1 5' flank \\
\hline Cs7 & 5'-gggactagtggatccttgaagtgagtcagccataaggacttaaattcacc-3' & C. sonorensis PDC1 3' flank \\
\hline Cs8 & 5'-aaggccttgtcgacgcggccgcttggttagaaaaggttgtgccaatttagcc-3' & C. sonorensis PDC1 $3^{\prime}$ flank \\
\hline $\operatorname{Cs} 26$ & 5'-gggacgggeccgcggecgcttacagcagcaaacaagtgatgcc-3' & C. sonorensis PDC2 $5^{\prime}$ flank \\
\hline Cs27 & 5'-ccctgggcccctcgagtttgatttatttgctttgtaaagagaa-3' & C. sonorensis PDC2 5' flank \\
\hline $\operatorname{Cs} 29$ & 5'-tggactagttagatagcaattcttacttgaaaaattaattgaagcattacc-3' & C. sonorensis PDC2 $3^{\prime}$ flank \\
\hline $\operatorname{Cs} 30$ & 5'-ggcccgcggccgctaaatataattatcgcttagttattaaaatgg-3' & C. sonorensis PDC2 $3^{\prime}$ flank \\
\hline
\end{tabular}

for the isolation of the corresponding genes from a genomic library. The identity of the purified genomic clones was verified by DNA sequencing.

\section{Southern and colony/plaque hybridizations}

Southern blots were prepared using conventional techniques and hybridized with probes labeled with $\left[\alpha-{ }^{32} \mathrm{P}\right]$ dATP or $\left[\alpha^{-32} \mathrm{P}\right] \mathrm{dCTP}$ (Amersham Pharmacia, Little Chalfont, UK) or with digoxigenin-11-dUTP (Roche, Mannheim, Germany). The presence and copy number of the $L D H$ gene was verified by Southern analysis of HindIII digested yeast DNA using the corresponding $L D H$ gene as the probe (see Table 2 for probe PCR primers). The $P D C 1$ - or $P D C 2$ deletions were verified by Southern analyses by the absence of $P D C 1$ - or $P D C 2-$ specific hybridization signals and the appearance of transformation marker-specific signals of appropriate size. PDC1 or PDC2 probes correspond to nucleotides in the deleted area and were amplified by PCR. Radioactive hybridization signals were detected by scanning exposed storage phosphor screens using the Typhoon 8600 variable mode imager (Molecular Dynamics, Sunnyvale, CA). Non-radioactive signals were detected colorimetrically with NBT and BCIP (Promega, Madison, WI).

\section{Plasmid construction}

Plasmids were constructed using conventional techniques [27]. Oligonucleotides were purchased from Sigma Genosys (Haverhill, UK). Dynazyme EXT or Phusion ${ }^{\mathrm{TM}}$ polymerase (Finnzymes, Espoo, Finland) were used for routine PCR amplification. The S. cerevisiae MEL5 gene (Genbank accession number Z37511) [30,31] was obtained as a $2.2 \mathrm{~kb}$ EcoRI-SpeI fragment from plasmid pMEL5-39 and ligated to EcoRI-SpeI cut pBluescript II KS(-) (Stratagene). The 
$1.5 \mathrm{~kb}$ C. sonorensis PGK1 promoter was amplified with primers 5423 and 5439 (Table 2) from a PGK1 lambda clone isolated from the genomic library and inserted upstream of the MEL5 ORF using SphI and XhoI enzymes resulting in pMI234 (Table 3). A similar strategy was used to construct pMI238 (Table 3) that contains the $0.6 \mathrm{~kb} C$. sonorensis GAPDH (TDH1) promoter, amplified with primers 5441 and 5440, upstream of MEL5. The $1.3 \mathrm{~kb} \mathrm{NcoI-BamHI} \mathrm{frag-}$ ment of pVR1 (V. Rajgarhia, NatureWorks LLC) containing the $L h L D H$ gene and the $S$. cerevisiae CYC1 terminator was ligated to the $1.5 \mathrm{~kb} C$. sonorensis PGK1 promoter, which was amplified with primers 5423 and 5427, and alternatively, to the $0.6 \mathrm{~kb}$ C. sonorensis $T D H 1$ promoter amplified with primers 5441 and 5440. The $L h L D H$ expression cassette obtained as a $3.4 \mathrm{~kb}$ AvrII-NheI fragment, was inserted into SpeI digested pMI234 resulting in pMI246 (Table 3). pMI246 was further modified in two steps for the replacement of PDC1. The C. sonorensis PDC1 3' homology region inserted downstream of the $L h L D H$ expression cassette, was amplified from genomic DNA using primers Cs7 and Cs8 (Table 2), digested with BamHI and NotI and ligated with BamHI-NotI digested pMI246 (8.9 kb), generating pMI256 (Table 3). The PDC1 5' homology region, inserted upstream of the MEL5 marker cassette, was amplified with primers Cs5 and Cs6 (Table 2), digested with ApaI, and ligated with the $9.8 \mathrm{~kb}$ pMI256 linearised with ApaI, generating pMI257 that contains $C$. sonorensis PDC1 5' homology region (0.8 kb), C. sonorensis PGK1 promoter, S. cerevisiae MEL5, C. sonorensis PGK1 promoter, L. helveticus ldhL (LhLDH) [19], S. cerevisiae CYC1 terminator and C. sonorensis PDC1

\begin{tabular}{|c|c|}
\hline Plasmid & Relevant content \\
\hline pMI234 & $\mathrm{CSP}_{P G K 1}-\mathrm{SCMEL5}$ \\
\hline pMI238 & $\mathrm{CSP}_{T D H 1}$ SCMEL5 \\
\hline pMI246 & $C_{S} P_{P G K 1}-S C M E L 5-S C T_{M E L 5}-C_{S} P_{P G K 1}-L h L D H-S C T_{C Y C 1}$ \\
\hline pMI247 & $C_{S} P_{G P D 1}-S C M E L 5-S C T_{M E L 5}-C_{S} P_{P G K 1}-L h L D H-S C T_{C Y C 1}$ \\
\hline pMI257 & $\begin{array}{l}\text { CSPDC1 5' - CSPPGK1 }-S C M E L 5-S C T_{M E L 5}-C_{S} P_{P G K 1}-L h L D H-S C T_{C Y C 1}- \\
\text { CSPDC1 3' }\end{array}$ \\
\hline pMI265 & CSPDC1 5' - CSPP P 1 -SCMEL5-SCT $T_{M E L L 5}-C_{S P} P_{P G K 1}-B m L D H-C S P D C 13^{\prime}$ \\
\hline pMI266 & CSPDC1 5' - CSPPPGI-SCMEL5-SCT $T_{M E L L}-C_{S} P_{P G K 1}-R O L D H-C S P D C 13^{\prime}$ \\
\hline pMI267 & $C S P D C 15^{\prime}-C S P_{P G K 1}-S C M E L 5-S C T_{M E L 5}-C S P_{P G K 1}-C S P D C 13^{\prime}$ \\
\hline pMI268 & $\operatorname{CSP} P_{P_{K K} 1} 1-G 418^{R}-S C T_{G A L 10}$ \\
\hline pMI269 & $C S P_{G P D 1}-G 418^{R}-S C T_{G A L 10}$ \\
\hline pMI278 & $C S P_{G P D 1}-G 418^{R}-S C T_{M E L 5}-C S P_{P G K 1}-B m L D H-S C T_{G A L 10}$ \\
\hline pMI279 & CSPDC2 5' - CSP $P_{G P D 1}-G 418^{R}-S C T_{M E L 5}-C_{S} P_{P G K 1}-B m L D H-S C T_{G A L 10}$ \\
\hline pMI286 & $\begin{array}{l}\text { CSPDC2 } 5^{\prime}-C S S_{G P D 1}-G 418^{R}-S C T_{M E L L}-C S P_{P G K 1}-B m L D H-S C T_{G A L 10}- \\
\text { CSPDC2 3' }\end{array}$ \\
\hline pMI287 & CSPDC2 5'-CSPP $P_{G D 1}-G 418^{R}-S C T_{M E L 5}-C_{S} P_{P G K 1}-C S P D C 23^{\prime}$ \\
\hline pMI288 & $\begin{array}{l}\text { CSPDC2 5'-CSPP } 5_{G D 1^{-}}-G 418^{R}-S C T_{M E L L 5}-C S P_{P G K 1}-L h L D H-S C T_{C Y C 1}- \\
\text { CSPDC2 3' }\end{array}$ \\
\hline
\end{tabular}

3' homology region $(0.9 \mathrm{~kb})$, in that order (Table 3$)$. It was modified by replacing the $L h L D H$ with $B$. megaterium ldh (BmLDH; GenBank accession no. M22305) in pMI265 or the $R$. oryzae ldhA (RoLDH, GenBank accession AF226154) [20] in pMI266 (Table 3). A control vector lacking $l d h L$, pMI267 (Table 3), was constructed by removing the $l d h L$ from pMI257 with $\mathrm{NcoI}$ and BamHI digestion, filling the overhangs in, and circularizing the $9.2 \mathrm{~kb}$ fragment.

The $G 418^{\mathrm{R}}$ gene was amplified with primers G418-5' and G418-3' (Table 2) from pPIC9K (Invitrogen), the $0.8 \mathrm{~kb}$ PCR product was digested with $\mathrm{BamHI}$ and $\mathrm{XbaI}$ and ligated to the $4.2 \mathrm{~kb} B a m \mathrm{HI}-X b a \mathrm{I}$ fragment of pNC101 (E. Jarvis, NREL, Golden, CO, USA) between $S$. cerevisiae PGK1 promoter and terminator generating pMI260. The promoter was replaced by the $C$. sonorensis TDH1 promoter, which was amplified from pMI238 with primers 5441 and Cs1, made blunt ended, digested with $X b a \mathrm{I}$, and ligated with the $4.2 \mathrm{~kb}$ PstI (blunt)-XbaI fragment of pMI260 to generate pMI269 (Table 3). pMI268 (Table 3), that contains the C. sonorensis PGK1 promoter amplified with primers 5423 and Cs2 (Table 2) from pMI234, upstream of $G 418^{\mathrm{R}}$, was constructed similarly as pMI269.

Plasmids for replacement of the $P D C 2$ locus containing C. sonorensis PDC2 $5^{\prime}$ homology region $(0.8 \mathrm{~kb}), C$. sonorensis GPD1 promoter, E. coli $G 418^{\mathrm{R}}$, S. cerevisiae MEL5 terminator, $C$. sonorensis PGK1 promoter, one of the $L D H$ genes, S. cerevisiae GAL10 terminator and $C$. sonorensis PDC2 3' homology region $(0.9 \mathrm{~kb})$, were prepared as follows. The BmLDH from pMI265 and the G418 ${ }^{\mathrm{R}}$ expression cassettes were joined to form pMI278 (Table 3). The region upstream of PDC2 ORF was amplified by PCR using the primers Cs26 and Cs27 (Table 2), and the genomic copy of the $C$. sonorensis PDC2 as the template (GenBank accession number AM420320), and the PCR product was inserted upstream of the LDH expression cassette resulting in plasmid pMI279. Then the 0.9 kb PDC2 3' homology region amplified by PCR as above using primers Cs29 and Cs30 (Table 2) was added to form pMI286. $B m L D H$ in pMI286 was replaced by $L h L D H$ resulting in pMI288. pMI287 was constructed by removing $B m L D H$ from pMI286.

\section{Transformation of $C$. sonorensis}

All plasmids were digested with restriction enzymes prior to transformation to facilitate integration into the genome, unless otherwise stated. C. sonorensis was transformed using the lithium acetate method [32,33]. After 3 hours incubation in liquid YPD medium, cells were spread onto agar-solidified YPD medium containing $200 \mu \mathrm{g} / \mathrm{ml} \mathrm{G-418}$ sulfate, or $40 \mu \mathrm{g} / \mathrm{ml} \mathrm{X- \alpha -Gal} \mathrm{(ICN} \mathrm{Biochemicals,} \mathrm{Aurora,}$ $\mathrm{OH}$, USA), a chromogenic substrate of $\alpha$-galactosidase. Cells transformed with NotI digested pMI257 ( $L h L D H)$, pMI265 (BmLDH), pMI266 (RoLDH), or pMI267 (no 
$L D H)$ were selected for melibiase activity, and with pMI286 (BmLDH), pMI287 (no $L D H$ ) or pMI288 $(L h L D H)$ were selected for G418 resistance. The PDC2 gene was replaced by the $G 418^{\mathrm{R}}$ gene in the $p d c 1$ deleted, melibiase positive $C$. sonorensis transformants containing the $L h L D H, B m L D H, R o L D H$, or no $L D H$ by transformation with pMI287 (no $L D H$ ). In addition, PDC2 was replaced by the $G 418^{\mathrm{R}}$ and $L D H$ genes by introducing a second copy of $L h L D H$ or $B m L D H$ into strains containing the $L h L D H$ or $B m L D H$ gene, respectively, integrated in the PDC1 locus. Putative PDC2 deletants were screened for decreased ethanol production. Replacements of $P D C 1$ or $P D C 2$ genes and the presence of $L D H$ were verified by Southern analyses. Strains constructed in this work are listed in Table 4.

\section{PDC and LDH enzyme activity measurements}

Enzyme activities were measured from freshly prepared cell extracts. Cells from $5 \mathrm{ml}$ samples were harvested by centrifugation, washed with $1 \mathrm{ml}$ of ice-cold $10 \mathrm{mM} \mathrm{K}_{2} \mathrm{HPO}_{4} /$ $\mathrm{KH}_{2} \mathrm{PO}_{4}, \mathrm{pH} 7.5,2 \mathrm{mM}$ EDTA, then with $1 \mathrm{ml}$ of homogenization buffer $\left[\left(100 \mathrm{mM} \quad \mathrm{KH}_{2} \mathrm{PO}_{4} / \mathrm{K}_{2} \mathrm{HPO}_{4}\right.\right.$, $\mathrm{pH}$ 7.5, $2 \mathrm{mM} \mathrm{MgCl}$, $1 \mathrm{mM}$ DTT containing protease inhibitors (Complete Mini, EDTA free, Roche)], resuspended

\begin{tabular}{|c|c|}
\hline Description & Transformed with plasmid(s) \\
\hline $\operatorname{pdc} 1 \triangle$ & pMI267 \\
\hline$p d c 2 \triangle$ & pMI287 \\
\hline$p d c 1 \Delta p d c 2 \Delta$ & pMI267, pMI287 \\
\hline$p d c 1 \triangle \because B m L D H$ & pMI265 \\
\hline$p d c 2 \triangle \because B m L D H$ & pMI286 \\
\hline$p d c 1 \triangle: B m L D H$ pdc2 $\triangle$ & pMI265, pMI287 \\
\hline$x: B m L D H$ & pMI265 \\
\hline$x:: B m L D H \quad y:: B m L D H$ & pMI265 \\
\hline$x:: L h L D H$ & $\mathrm{pMI} 246$ \\
\hline$x:: L h L D H$ & $\mathrm{pMI} 247$ \\
\hline$x:: L h L D H$ y::LhLDH & pMI257 \\
\hline$x:: L h L D H-L h L D H-L h L D H$ & $\mathrm{pMI} 247$ \\
\hline$p d c 1 \triangle: L h L D H$ & pMI257 \\
\hline pdc1 $\triangle: R o L D H$ & pMI266 \\
\hline$p d c 1 \triangle: L h L D H$ pdc2 $\triangle$ & pMI257, pMI287 \\
\hline$p d c 1 \Delta: R o L D H$ pdc2 $\triangle$ & pMI266, pMI287 \\
\hline$p d c 1 \Delta: L h L D H$ pdc2 $2: L h L D H$ & pMI257, pMI288 \\
\hline$p d c 1 \triangle: B m L D H$ pdc2 $2: B m L D H$ & pMI265, pMI286 \\
\hline
\end{tabular}

The heterologous $L h L D H, B m L D H$, and RoLDH genes were expressed under the control of the $C$. sonorensis PGK1 promoter; the MEL5 and $G 418^{\mathrm{R}}$ marker genes were expressed under the $C$. sonorensis GPD1 or PGK1 promoter (not indicated in the table). $x::$ and $y::$ indicate that the site of integration is not known. Two consecutive transformations were made to construct a strain where two plasmids are listed. in $0.75 \mathrm{ml}$ of homogenization buffer and homogenized with $0.75 \mathrm{ml}$ glass beads using a Mini Bead Beater (BioSpec Products, Bartlesville, OK) for $4 \times 30$ seconds. Samples were centrifuged at $14000 \mathrm{rpm}$ for $30 \mathrm{~min}$ at $4^{\circ} \mathrm{C}$. PDC activity was determined spectrophotometrically $\left(\mathrm{A}_{340}\right)$ with a Cobas Mira automated analyser at $30^{\circ} \mathrm{C}$ in $40 \mathrm{mM}$ imidazole- $\mathrm{HCl}(\mathrm{pH}$ 6.5) containing $0.2 \mathrm{mM} \mathrm{NADH}$, $50 \mathrm{mM} \mathrm{MgCl}_{2}, 0.2 \mathrm{mM}$ thiamine pyrophosphate, 90 units alcohol dehydrogenase, and $50 \mathrm{mM}$ pyruvate. LDH enzyme activity in the supernatant was determined spectrophotometrically $\left(\mathrm{A}_{340}\right)$ with a Cobas Mira automated analyzer at $30^{\circ} \mathrm{C}$ in $50 \mathrm{mM}$ sodium acetate $(\mathrm{pH} 5.2)$ and in $50 \mathrm{mM}$ imidazole- $\mathrm{HCl}$ ( $\mathrm{pH}$ 6.5) buffer, each containing $0.4 \mathrm{mM}$ $\mathrm{NADH}, 5 \mathrm{mM}$ fructose-1, 6-diphosphate (FBP) and $2 \mathrm{mM}$ pyruvate. $R$. oryzae $\mathrm{LDH}$ activity was measured in the presence and in the absence of FBP at pH 6.5. The activities are expressed in units per milligram protein (U/mg). $1 \mathrm{U}$ was defined as the amount of enzyme required to reduce $1 \mu \mathrm{mol}$ of substrates per min. Protein concentrations were measured using a protein assay reagent (Bio-Rad 500-0006) and bovine serum albumin (Sigma) as the protein standard.

\section{Analytical methods}

The culture supernatants were analyzed by HPLC for lactic acid, glucose, pyruvic acid, acetic acid, glycerol and ethanol using a Waters 2690 Separation Module and Waters System Interphase Module liquid chromatography coupled with a Waters 2414 differential refractometer and a Waters 2487 dual $\lambda$ absorbance detector (Waters, Milford, MA). A Fast Juice Column (50 mm $\times$ $7.8 \mathrm{~mm}$, Phenomenex, Torrance, CA) and a Fast Acid Analysis Column (100 mm $\times 7.8 \mathrm{~mm}$, Bio-Rad, Hercules, CA) or, alternatively, a Fast Acid Analysis Column $(100 \mathrm{~mm} \times 7,8 \mathrm{~mm}$, Bio-Rad) and an Aminex HPX-87H Organic Acid Analysis Column $(300 \mathrm{~mm} \times 7.8 \mathrm{~mm}$, BioRad) were equilibrated with $2.5 \mathrm{mM} \mathrm{H}_{2} \mathrm{SO}_{4}$ in water at $60^{\circ} \mathrm{C}$ and samples were eluted with $2.5 \mathrm{mM} \mathrm{H}_{2} \mathrm{SO}_{4}$ in water at a $0.5 \mathrm{ml} / \mathrm{min}$ flow rate. Data were acquired with Waters Millennium software.

Undissociated lactic acid was determined from supernatant samples diluted in ethyl acetate. The standard was prepared by dissolving lithium lactate in $0.5 \mathrm{M} \mathrm{HCl}$ and further diluting it in ethyl acetate. Samples and standards were eluted with the Fast Juice Column $(50 \mathrm{~mm} \times$ $7.8 \mathrm{~mm}$, Phenomenex) and Fast Acid Analysis Column $(100 \mathrm{~mm} \times 7.8 \mathrm{~mm}$, Bio-Rad) as above at $1.0 \mathrm{ml} / \mathrm{min}$ flow.

Lactate and ethanol yields were calculated as the amounts of accumulated products per amount of consumed sugar. Yields are reported for the sample time when sugar concentration was first observed to be below $1.5 \mathrm{~g} / \mathrm{l}$, unless otherwise stated.

An $\mathrm{OD}_{600}$ of 1 corresponded to $0.3 \mathrm{~g} / \mathrm{l}$ cell dry weight. 
Intracellular concentrations of lactic acid and pyruvate were measured from cells harvested from $1 \mathrm{ml}$ of culture by centrifugation, washed with $1 \mathrm{ml} 1 \mathrm{M}$ Tris- $\mathrm{HCl}$ $\mathrm{pH}$ 9.0, resuspended in $1 \mathrm{ml}$ of ice cold $5 \%(\mathrm{w} / \mathrm{v})$ trichloroacetic acid by vortexing for $1 \mathrm{~min}$ and incubated on ice for $30 \mathrm{~min}$. Samples were vortexed for $1 \mathrm{~min}$, centrifuged at $13000 \mathrm{rpm}$ for $30 \mathrm{~min}$ at $+4^{\circ} \mathrm{C}$, and L-lactic acid in the supernatant was measured with the L-lactic acid UV method (\#10139084035, Roche, Mannheim, Germany) method or by HPLC. Pyruvate was measured enzymatically using a pyruvate kit (Sigma Diagnostics, St. Louis, MO). Intracellular concentrations of lactic acid and pyruvate were calculated assuming that one gram of cell dry weight corresponds to $2 \mathrm{ml}$ cell volume [34].

D-lactate was determined enzymatically with the Llactate UV-method (\#10139084035, Roche, Mannheim, Germany) using d-LDH instead of L-LDH in the assay.

\section{Statistical analyses}

Data are given as means. Where appropriate, values were compared by analysis of variance (ANOVA) and significant differences determined using Fisher's multiple range test. $P$ values $<0.05$ were considered statistically significant.

\section{Abbreviations}

PDC: Pyruvate decarboxylase enzyme; PDC: Gene encoding for pyruvate decarboxylase; $L$ LLDH: L-lactate dehydrogenase gene of Lactobacillus helveticus; BmLDH: L-lactate dehydrogenase gene of Bacillus megaterium; RoLDH: L-lactate dehydrogenase gene of Rhizopus oryzae; YP: 1\% (w/v) yeast extract - 2\% (w/v) peptone medium; X-a-Gal: 5-bromo-4-chloro-3-indolyl-aD-galactopyranoside; TDH1: Gene for glyceraldehyde-3-phosphate dehydrogenase; PGK1: Gene for 3-phosphoglycerate kinase.

\section{Competing interests}

PS is an employee of Cargill, which has financial interest in lactic acid producing microorganisms described here.

\section{Authors' contributions}

Ml designed and carried out the molecular studies, participated in the cultivations, analysed the results, and drafted the manuscript. KK carried out the metabolite and enzyme analytics, participated in the cultivations and the analysis of results. LR and MP helped to draft the manuscript. VR and MP conceived of the study. MP, LR, PS and VR participated in its design and coordination. All authors read and approved the final manuscript.

\section{Acknowledgements}

Dr. Marilyn Wiebe and Brian Rush are thanked for comments on the manuscript. Merja Helanterä and Seija Rissanen are thanked for excellent technical assistance. This work was supported by the United States Department of Energy Award No. DE-FC36-021D14349 to NatureWorks LLC.

\section{Author details}

${ }^{1} \mathrm{~V} T \mathrm{~T}$ Technical Research Centre of Finland, Espoo, Finland. ${ }^{2}$ Cargill Biotechnology Research and Development, Minnesota, USA. ${ }^{3}$ Present address: Total Gas and Power Biotech USA, Emeryville, California, USA.

\section{Received: 19 February 2013 Accepted: 19 May 2013}

Published: 25 May 2013

\section{References}

1. Datta R, Henry M: Lactic acid: recent advances in products, processes and technologies - a review. J Chem Technol Biotechnol 2006, 81(7):1119-1129.
2. Ishida N, Saitoh S, Onishi T, Tokuhiro K, Nagamori E, Kitamoto K, Takahashi $\mathrm{H}$ : The effect of pyruvate decarboxylase gene knockout in Saccharomyces cerevisiae on L-lactic acid production. Biosci Biotechnol Biochem 2006, 70(5):1148-1153.

3. Colombié S, Dequin S, Sablayrolles JM: Control of lactate production by Saccharomyces cerevisiae expressing a bacterial LDH gene. Enzyme Microb Technol 2003, 33(1):38-46.

4. Skory CD: Lactic acid production by Saccharomyces cerevisiae expressing a lactate dehydrogenase gene. J Ind Microbiol Biotechnol 2003, 30(1):22-27.

5. Bianchi MM, Brambilla L, Protani F, Liu CL, Lievense J, Porro D: Efficient homolactic fermentation by Kluyveromyces lactis strains defective in pyruvate utilization and transformed with the heterologous LDH gene. Appl Environ Microbiol 2001, 67(12):5621-5625.

6. Porro D, Bianchi MM, Brambilla L, Menghini R, Bolzani D, Carrera V, Lievense J, Liu CL, Ranzi BM, Frontali L, Alberghina L: Replacement of a metabolic pathway for large-scale production of lactic acid from engineered yeasts. Appl Environ Microbiol 1999, 65(9):4211-4215.

7. Ilmén M, Koivuranta K, Ruohonen L, Suominen P, Penttilä M: Efficient production of L-lactic acid from xylose by Pichia stipitis. Appl Environ Microbiol 2007, 73(1):117-123.

8. Osawa F, Fujii T, Nishida T, Tada N, Ohnishi T, Kobayashi O, Komeda T, Yoshida S: Efficient production of L-lactic acid by Crabtree-negative yeast Candida boidinii. Yeast 2009, 26(9):485-496.

9. Ikushima S, Fujii T, Kobayashi O, Yoshida S, Yoshida A: Genetic engineering of Candida utilis yeast for efficient production of L-lactic acid. Biosci Biotechnol Biochem 2009, 73(8):1818-1824.

10. Branduardi P, Valli M, Brambilla L, Sauer M, Alberghina L, Porro D: The yeast Zygosaccharomyces bailii: a new host for heterologous protein production, secretion and for metabolic engineering applications. FEMS Yeast Res 2004, 4(4-5):493-504.

11. Pecota DC, Rajgarhia V, Da Silva NA: Sequential gene integration for the engineering of Kluyveromyces marxianus. J Biotechno/ 2007, 127(3):408-416.

12. Dequin S, Barre P: Mixed lactic acid-alcoholic fermentation by Saccharomyces cerevisiae expressing the Lactobacillus casei L(+)-LDH. Biotechnology (N Y) 1994, 12(2):173-177.

13. Eberhardt I, Cederberg H, Li H, König S, Jordan F, Hohmann S: Autoregulation of yeast pyruvate decarboxylase gene expression requires the enzyme but not its catalytic activity. Eur J Biochem 1999, 262(1):191-201.

14. Ishida N, Saitoh S, Tokuhiro K, Nagamori E, Matsuyama T, Kitamoto K, Takahashi $\mathrm{H}$ : Efficient production of L-Lactic acid by metabolically engineered Saccharomyces cerevisiae with a genome-integrated L-lactate dehydrogenase gene. Appl Environ Microbiol 2005, 71(4):1964-1970.

15. Branduardi P, Sauer M, De Gioia L, Zampella G, Valli M, Mattanovich D, Porro $D$ : Lactate production yield from engineered yeasts is dependent from the host background, the lactate dehydrogenase source and the lactate export. Microb Cell Fact 2006, 5:4.

16. Saitoh S, Ishida N, Onishi T, Tokuhiro K, Nagamori E, Kitamoto K, Takahashi $\mathrm{H}$ : Genetically engineered wine yeast produces a high concentration of L-lactic acid of extremely high optical purity. App/ Environ Microbiol 2005, 71(5):2789-2792.

17. Meyer SA, Payne RW, Yarrow D: Candida Berkhout. In The Yeasts, a taxonomic study. Edited by Kurtzman CP, Fell JP. Amsterdam: Elsevier; 1998.

18. Ganter PF, Cardinali G, Giammaria M, Quarles B, Ganter PF, Cardinali G, Giammaria M, Quarles B: Correlations among measures of phenotypic and genetic variation within an oligotrophic asexual yeast, Candida sonorensis, collected from Opuntia. FEMS Yeast Res 2004, 4:527-540.

19. Savijoki K, Palva A: Molecular genetic characterization of the L-lactate dehydrogenase gene (IdhL) of Lactobacillus helveticus and biochemical characterization of the enzyme. Appl Environ Microbio/ 1997, 63(7):2850-2856.

20. Skory CD: Isolation and expression of lactate dehydrogenase genes from Rhizopus oryzae. Appl Environ Microbiol 2000, 66(6):2343-2348.

21. van Maris AJ, Winkler AA, Porro D, van Dijken JP, Pronk JT: Homofermentative lactate production cannot sustain anaerobic growth of engineered Saccharomyces cerevisiae: possible consequence of energy-dependent lactate export. Appl Environ Microbiol 2004, 70(5):2898-2905

22. Casal M, Paiva S, Queirós O, Soares-Silva I: Transport of carboxylic acids in yeasts. FEMS Microbiol Rev 2008, 32:974-994.

23. Pacheco A, Talaia G, Sà-Pessoa J, Bessa D, Conçalves MJ, Moreira R, Paiva S, Casal M, Queirós O: Lactic acid production in Saccharomyces cerevisiae is 
modulated by expression of the monocarboxylate transporters Jen 1 ja Ady2. FEMS Yeast Res 2012: . doi:10.1111/j.1567-1364.2012.00790.x.

24. Valli M, Sauer M, Branduardi P, Borth N, Porro D, Mattanovich D: Improvement of lactic acid production in Saccharomyces cerevisiae by cell sorting for high intracellular pH. Appl Environ Microbiol 2006, 72(8):5492-5499.

25. Piper P, Ortiz Calderon C, Hatzixanthis K, Mollapur M: Weak acid adaptation: the stress response that confers yeast with resistance to organic acid food preservatives. Microbiology 2001, 147:2635-2642.

26. Miller C, Fosmer A, Rush B, McMullin T, Beacom D, Suominen P: Industrial production of lactic acid. Comprehensive Biotechnology 2011, 3:179-188. http://dx.doi.org/10.1016/B978-0-08-088504-9.00177-X.

27. Sambrook J, Russell DW: Molecular cloning : a laboratory manual: 3rd ed. Cold Spring Harbor, N.Y:: Cold Spring Harbor Laboratory Press; 2001.

28. Hoffman CS, Winston F: A ten-minute DNA preparation from yeast efficiently releases autonomous plasmids for transformation of Escherichia coli. Gene 1987, 57(2-3):267-272.

29. IImén M, Thrane C, Penttilä M: The glucose repressor gene cre1 of Trichoderma: isolation and expression of a full-length and a truncated mutant form. Mol Gen Genet 1996, 251(4):451-460.

30. Naumov G, Turakainen H, Naumova E, Aho S, Korhola M: A new family of polymorphic genes in Saccharomyces cerevisiae: alpha-galactosidase genes MEL1-MEL7. Mol Gen Genet 1990, 224(1):119-128.

31. Turakainen $\mathrm{H}$, Kristo $\mathrm{P}$, Korhola M: Consideration of the evolution of the Saccharomyces cerevisiae MEL gene family on the basis of the nucleotide sequences of the genes and their flanking regions. Yeast 1994, 10(12):1559-1568.

32. Gietz D, St Jean A, Woods RA, Schiestl RH: Improved method for high efficiency transformation of intact yeast cells. Nucleic Acids Res 1992, 20(6):1425.

33. Hill J, Donald KA, Griffiths DE: DMSO-enhanced whole cell yeast transformation. Nucleic Acids Res 1991, 19(20):5791.

34. Gancedo C, Serrano R: Energy Yielding Metabolism. In The yeasts. Edited by Rose AH, Harrison JS. London, UK: Academic Press; 1989:3.

doi:10.1186/1475-2859-12-53

Cite this article as: Ilmén et al:: Production of L-lactic acid by the yeast Candida sonorensis expressing heterologous bacterial and fungal lactate dehydrogenases. Microbial Cell Factories 2013 12:53.

\section{Submit your next manuscript to BioMed Central and take full advantage of:}

- Convenient online submission

- Thorough peer review

- No space constraints or color figure charges

- Immediate publication on acceptance

- Inclusion in PubMed, CAS, Scopus and Google Scholar

- Research which is freely available for redistribution 